\title{
The non-brain anterior nerve center and tentacle crown structure of Owenia borealis (Annelida, Oweniidae): the evolution of the nervous system and tentacles in Bilateria
}

Nadezhda Rimskaya-Korsakova

Moscow State University

Vyacheslav Dyachuk

Russian Academy of Sciences

Elena Temereva ( $\nabla$ temereva@mail.ru )

Moscow State University https://orcid.org/0000-0001-7791-0553

\section{Research Article}

Keywords: medullary dorsal commissure, stratified neuroepithelium

Posted Date: June 23rd, 2021

DOI: https://doi.org/10.21203/rs.3.rs-622783/v1

License: (c) (i) This work is licensed under a Creative Commons Attribution 4.0 International License.

Read Full License 
1 The non-brain anterior nerve center and tentacle crown structure of Owenia borealis

2 (Annelida, Oweniidae): the evolution of the nervous system and tentacles in Bilateria

3 Nadezhda Rimskaya-Korsakova ${ }^{1}$, Vyacheslav Dyachuk ${ }^{2}$, Elena Temereva ${ }^{1,3, *}$

4

$5 \quad{ }^{1}$ Department of Invertebrate Zoology, Biological faculty, Moscow State University, Moscow

6 119992, Russia; nadezdarkorsakova@gmail.com;

$7 \quad{ }^{2}$ National Scientific Center of Marine Biology, Far Eastern Branch, Russian Academy of

$8 \quad$ Sciences, Vladivostok 690041, Russia; slavad83@gmail.com

$9 \quad{ }^{3}$ National Research University Higher School of Economics, Moscow, Russia;

10 temereva@mail.ru

11 E-mail: temereva@mail.ru; nadezdarkorsakova@gmail.com; slavad83@gmail.com

*Correspondence to: E.N. Temereva, Department of Invertebrate Zoology, Biological

14 Faculty, Lomonosov State University, Leninskie Gory 1, bld. 12, Moscow 119992, Russian

15 Federation

16

17 Tel.: +7(495)939-56-95

$18 \quad$ Fax.: +7(495)939-56-95

19 E-mail: temereva@mail.ru 
22 The Oweniidae are marine annelids with many unusual features of organ system, development, morphology, and ultrastructure. Together with magelionds, oweniids have been placed within the Palaeoannelida, a sister group to all remaining annelids. The study of this group may increase our understanding of the early evolution of annelids (including their radiation and diversification) and of the morphology of the last common bilaterian ancestor. In the current research, scanning electron microscopy revealed that the tentacle apparatus consists of 10 branched arms. The tentacles are covered by monociliary cells that form a ciliar groove that extends along the oral side of the arm base. Light, confocal, and transmission electron microscopy revealed that head region contains two circular intraepidermal nerves (outer and inner) that give rise to the neurites of each tentacle, i.e., intertentacular neurites are absent. Each tentacle contains a coelomic cavity with a network of blood capillaries. Monociliar myoepithelial cells of the tentacle coelomic cavity form both the longitudinal and the circular muscles. The structure of this myoepithelium is intermediate between simple and pseudo-stratified myepithelium. Overall, tentacles lack prominent zonality, i.e., co-localization of ciliary zones, neurite bundles, and muscles. This organization, which indicates a non-specialized tentacle crown in $O$. borealis and other oweniids with tentacles, is probably ancestral for annelids and for all Bilateria. The outer circular nerve of $O$. borealis is a dorsal medullary commissure that apparently functions as an anterior nerve center and is organized at the ultrastructural level as a stratified neuroepithelium. Given the hypothesis that the anterior nerve center of the last bilateral ancestor might be a diffuse neural plexus network, these results suggest that the ultra anatomy of that plexus brain might be a stratified neuroepithelium. Alternatively, the results could reflect the simplification of structure of the anterior nerve center in some bilaterian lineages.

Keywords: medullary dorsal commissure, stratified neuroepithelium, 


\section{Background}

49

50

51

52

53

54

55

56

57

58

59

60

61

62

The Annelida is a phylum of bilaterian animals and is the central clade of the Lophotrochozoa superphylum. Annelids exhibit extremely wide patterns of organ system anatomy and ultrastructure (1). According to recent data, the Annelida can be divided into two large clades, Errantia and Sedentaria, and also includes several sister groups, so-called basal branching lineages, including oweniids, chaetopterids, amphinomids, sipunculids, etc. (2-7). Members of the family Oweniidae have many unusual morphological, ultrastructural, and developmental characteristics (8-16). Oweniids together with magelonids have been recently placed among the Palaeoannelida, a sister group to all remaining annelids $(5,7)$. The study of oweniids may increase our understanding of the evolution of annelids, including their radiation and diversification. An improved understanding of annelid evolution should increase our understanding of the morphology of the last common bilaterian ancestor (LCBA).

At present, there are two main hypotheses regarding the structure of the anterior nerve center of the LCBA: it consisted of either a ganglionic accumulation of neurons or a diffuse nerve plexus $(17,18)$. The first hypothesis suggests that the LCBA could be simple ganglia, or even an elaborated brain, defined as a central collection of neuronal centers with distributed and hierarchical functions $(19,20)$. The organizations of the ganglia and brains have been well studied (21-23). The second hypothesis suggests that the anterior nerve center is organized as a nerve plexus, or a non-ganglionic intraepidermal anterior nerve center $(7,15,23-30)$. Unfortunately, the detailed structure of the non-ganglionic intraepidermal anterior nerve center has not been described for bilaterians, especially for annelids, which form the central clade of the Lophotrochozoa.

One interesting question concerning the LCBA is whether it had tentacle-like appendages. In recent metazoans, tentacles are used for food collection by cnidarians and ctenophores, as well as by many bilaterian groups including phoronids, brachiopods, bryozoans, entoprocts, 
annelids, mollusks, hemichordates, echinodermes, and chordates $(1,31)$. The presence of tentacles in many groups suggests that the LCBA may have also had tentacles. If tentacles are inherited from the LCBA, they must have evolved in different directions among bilaterians. Although the directions of tentacle evolution remain uncertain, we know that some organisms have specialized tentacles (32-38). This specialization is expressed in the zonation and colocalization of several organ systems: ciliary bands, nerve cords, and muscles (39-47). Such specialized tentacles are present in the lophophorates (48-51). To increase our understanding of how tentacles have evolved among the Bilateria, we require detailed data on the organization and development of tentacles from different groups of recent bilaterians.

All oweniids have an intraepidermal non-ganglionic nerve center $(11-13,15,26)$, but its ultrastructural organization remains unclear. The family Oweniidae includes genera that have tentacles (Owenia and Myriowenia) and those that lack tentacles (Galathowenia and Myriochele) (52). Tentacles of Owenia fusiformis were briefly studied in the past, i.e., the cells on the oral side of the tentacles have been described $(53,54)$. Considering that the morphology of oweniids is highly relevant to discussions of the structure of the last common ancestor of the Annelida, in the current report we provide a detailed description of the anatomy and ultra-anatomy of the head and tentacle apparatus of Owenia borealis. We also consider the relevance of the data to the evolution of the structure of the nerve center and tentacles in Bilateria.

\section{Materials and Methods}

About 20 adults of Owenia borealis Koh, Bhaud \& Jirkov, 2003 (55) were collected in September 2018 near the Espegrend Marine Biological Station, University of Bergen, Norway. Live adults were extracted from their tubes and were used for the research.

\section{Scanning electron microscopy (SEM)}


The structure of the head was studied by scanning electron microscopy (SEM). The head fragments were postfixed in $1 \% \mathrm{OsO} 4$ and dehydrated in an ascending ethanol and acetone series, critical point dried, and then sputter coated with platinum-palladium. Specimens were examined with a JEOL JSM-6380LA (JEOL Ltd., Tokyo, Japan) microscope at operating voltages of $15-20 \mathrm{kV}$ at Lomonosov Moscow State University.

\section{Transmission electron microscopy (TEM)}

The head regions with tentacles were fixed overnight at $4^{\circ} \mathrm{C}$ in a $2.5 \%$ solution of glutaraldehyde in $0.2 \mathrm{M}$ phosphate buffer (PBS). The heads were then washed in 0.2 M PBS for $4 \mathrm{~h}$ with three changes and postfixed in $1 \% \mathrm{OsO}_{4}$ in $0.2 \mathrm{M}$ PBS for $3 \mathrm{~h}$ at room temperature (RT) with gentle rotation. The specimens were then dehydrated in an increasing series of ethanol concentrations (from 15 to 96\%) and isopropanol. They were subsequently infiltrated in a mixture of isopropanol and Spurr resin for 3 days and then embedded in pure Spurr resin at $60^{\circ} \mathrm{C}$ for $24 \mathrm{~h}$.

The anterior part of the body of two adults embedded in resin were used to prepare a complete series of $1-\mu \mathrm{m}$ (semi-thin) and 70-nm (thin) resin sections with a Leica UC 7 ultramicrotome (Leica Microsystems, Wetzlar, Germany). The semi-thin sections were stained with methylene blue and examined with a Zeiss Axioplan2 light microscope equipped with an AxioCam HRm camera (Carl Zeiss Microscopy, LLC, USA). Semi-thin sections were used for description of gross anatomy and for 3D reconstructions. The thin sections were stained with uranyl acetate and lead citrate and were examined with a JEM-1011 JEOL or a JEM-100 B-1 JEOL transmission electron microscope (JEOL, Akishima, Japan).

\section{Whole-mount immunostaining and confocal laser scanning microscopy (CLSM)}

Adults were fixed in a $4 \%$ paraformaldehyde solution in PBS (pH 7.4) (ThermoFisher Scientific, Pittsburgh, PA, USA) for $8 \mathrm{~h}$ at $4^{\circ} \mathrm{C}$ and then were washed three times (30 min each time) in PBS with 1\% Triton X-100 (PBT) (ThermoFisher Scientific). The specimens 
were then placed in a mixture of normal goat serum and PBT (NGS 15\%) for $2 \mathrm{~h}$ to block the

124 sites of unspecific staining. For immunostaining, solution of primary antibodies (Abs) antirabbit 5-HT (Immunostar, 20080, 1:1000) alone or in combination with anti- $\alpha$-acetylated mouse tubulin (Santa Cruz, sc-23950, 1:1000) in PBT were used. The animals were incubated in primary $\mathrm{Abs}$ for $24 \mathrm{~h}$ at $4{ }^{\circ} \mathrm{C}$ with rotation, followed by triple rinses with PBT. The secondary antibody mixtures consisted of donkey anti-rabbit (DAR) 488 (Life Technologies, A21206, 1:1000) with donkey anti-mouse (DAM) 555 (Life Technologies, A31572, 1:1000) in PBT, for $24 \mathrm{~h}$ at $4^{\circ} \mathrm{C}$. After antibodies labeling, specimens were placed in a 1:30 dilution of AlexaFluor 488 phalloidin for detection F-actin together with 1:100 dilution of 4', 6diamidino-2-phenylindole (DAPI, Molecular Probes, USA,) in PBT for $4 \mathrm{~h}$ at RT. As a control for non-specific immunorecognition, we performed immunohistochemical staining immunized) immunoglobulin G (1:500-1:1000; Sigma-Aldrich; I5006, I5381). The specimens were then washed three times in PBS, washed for several minutes in increasing concentrations of isopropanol, and embedded in Murray Clear (a 50/50 mixture of benzyl benzoate and benzyl alcohol) at RT. Specimens were observed with a Zeiss LSM 780 confocal microscope (Far Eastern Center of Electron Microscopy, A.V. Zhirmunsky National Scientific Center of Marine Biology, Far Eastern Branch of the Russian Academy of Sciences, Vladivostok, Russia) and with with a Nikon Eclipse Ti confocal microscope (Nikon Corporation, Tokyo, Japan) at Lomonosov Moscow State University, Moscow, Russia.

\section{Image processing}

Z-projections were prepared using ImageJ software (56). Volume renderings were prepared with Amira version 5.2.2 software (ThermoFisher Scientific, MA, USA). Images were processed in Adobe Photoshop CS3 (Adobe Systems, San Jose, CA, USA). Threedemensional reconstructions were prepared with Imaris 7.2.1 software (ThermoFisher Scientific, MA, USA). 
Our observations indicated that the tentacle crown of $O$. borealis is not symmetrical and is formed by two lateral groups, which are separated on the dorsal and ventral sides. Each lateral group is represented by five short tentacles, which included (from the ventral to the dorsal side) 2 double tentacles, 1 quadruple tentacle, and 1 double tentacle on the right side or 1 triple tentacle and 1 quadruple tentacle on the left side (Figure 1A). There are two levels of tentacle ramification: for the first level, each tentacle arm splits into two or four branches; for the second level, each tentacle is split into bifid tips. Tentacles and their arms are covered by cilia, which are abundant on the oral side and are almost absent on the aboral side (Fig. 1D-F, 2A). The base of the tentacles has a deep groove extending along the oral side (Fig. 2B, C). This groove is prominent at the base of the tentacle arm (Fig. 2C). The base of the tentacle crown forms a collar that extends along external side of the head (Fig. 1C). The ventral pharyngeal organ, consisting of the dorsal and ventral lips, is very large and is located at the ventral side of the tentacle crown. Two ventrolateral lips are adjacent to the ventral pharyngeal organ and are covered by cilia (Fig. 1C). The mouth resembles a crescent slit (Fig. 1A). The base of the tentacle apparatus is surrounded by a thin collar fold from the outside of the tentacle crown (Fig. 1A).

\section{Histology and ultrastructure of the tentacles and head}

Epithelium. Each tentacle is covered by ciliated epithelial cells and contains a coelomic cavity that contains muscles and blood vessels (Fig. 3A, B). The aboral epithelium is formed by large monociliated cells, which are filled with many vesicles of different diameter (Fig. 4A). These cells form the basal thin projections that contain electron-dense filaments, surround the neurite bundles, and attach to the basal lamina (Fig. 4A). Large gland cells of different types are scattered in the epithelium of the aboral side (Fig. 2A, C). Some of these cells have large vacuoles and electron-lucent content (Fig. 2A, C), and others have many 

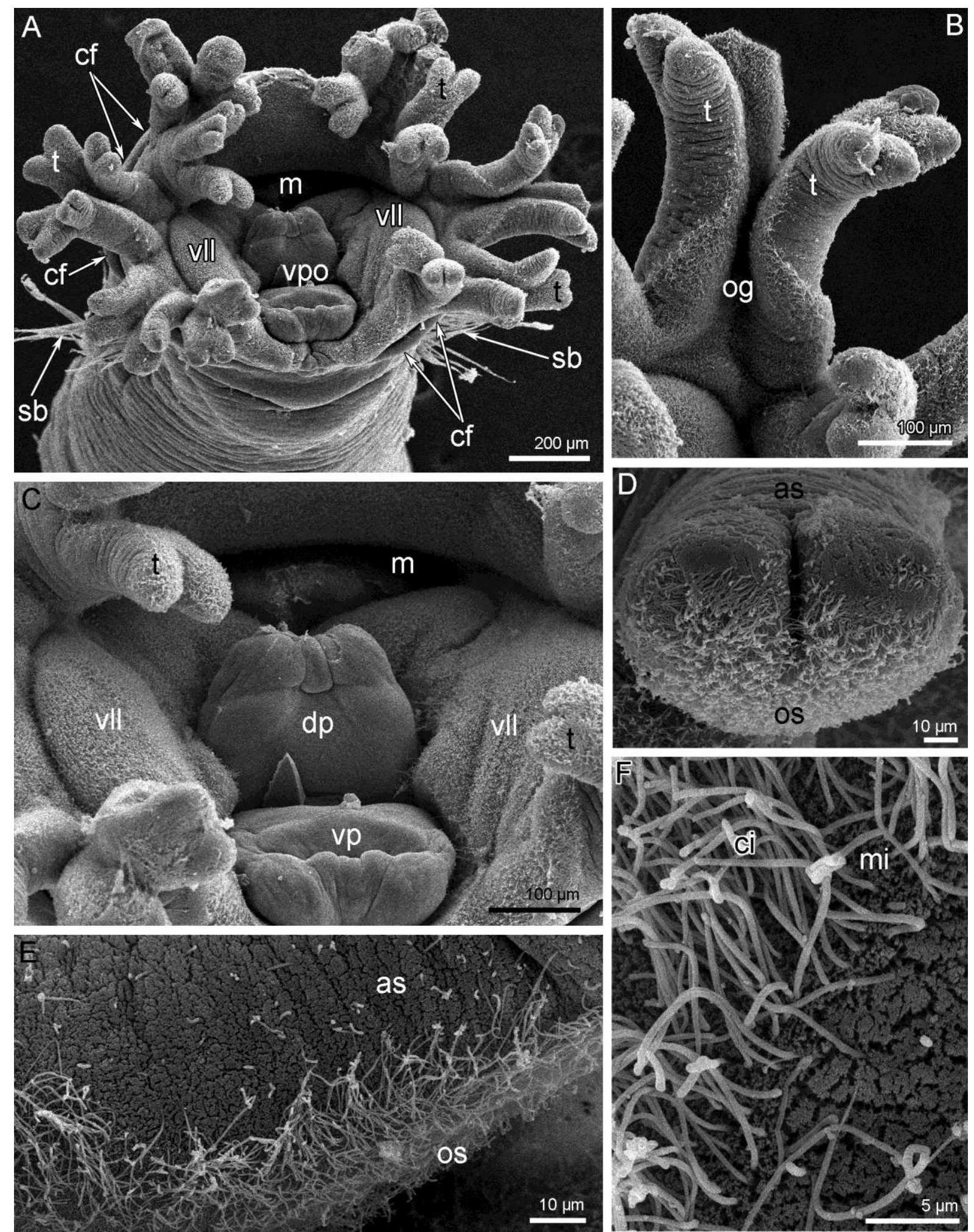

Figure 1. Morphology of the head and tentacles of Owenia borealis (SEM). (A) The head viewed from the top. (B) Tentacle. (C) Ventral pharyngeal organ. (D) Forked tip of tentacle. (E) Ciliated oral and non-ciliated aboral sides of tentacle. (F) A portion of the oral side of tentacle. Abbreviations: as aboral side; cf - collar fold; ci - cilia; dp - dorsal part of pharyngeal organ; m - mouth; mi microvilli; og - oral groove; os - oral side; sb - setae bundle; $t$ - tentacle; vll - ventrolateral lip; vp ventral part of pharyngeal organ.

small and dense granules in the cytoplasm (Fig. 2B, C). Longitudinal neurite bundles extend along the base of the aboral epithelium, which also contains cells with different organization 
(Fig. 4A, B). Some of these basal cells are small roundish perikarya, which cytoplasm contains synaptic vesicles. Other basal cells contain ovoid electron-dense granules, therefore their projections with the same granules can be easily recognized between neurite bundles (Fig. 4B). Other cells form large thin and thick projections, which contain electron-dense intermediate filaments and synaptic vesicles (Fig. 4B).

The epithelium of the oral side consists of slender high cells, which bear cilium and do not form prominent basal projections (Fig. 4C). The cytoplasm of these cells contains prominent, apical transverse and longitudinal electron-dense fibers. The epithelium of the oral side contains many glandular cells, whose cytoplasm is filled with roundish vesicles with flocculent content (Fig. 3A). The secretory apparatus and nucleus are located in the basal part of the glandular cells. Neurite bundles, which extend between the basal parts of the epithelial cells, are less numerous than in aboral epithelium (Fig. 4C). Perikarya and cells with ovoid electron-dense granules are scattered in the basal portion of the epithelium of the oral side (Fig. 4C).

The epithelium lies on the extracellular matrix layer (ECM) (Fig. 3A, B). On the aboral side, the ECM has waves and forms invaginations that contain the bundles of muscles. The aboral ECM is up to $2 \mu \mathrm{m}$ thick (Fig. 3B). The ECM is $2-3$ times thinner on the oral side than on the aboral side of the tentacle (Fig. 3A).

Coelomic cavity and musculature. The coelomic cavity of the tentacles is connected to the voluminous cavity of first body segment (i.e., the head cavity), which is formed by the prostomium and peristomium (Figs. 5A, 6A). The lower border of the head cavity forms ventral and dorsal projections (Fig. 5A). On the ventral side, the head cavity is occupied by a large ventral pharyngeal organ that extends to the lower border of the head cavity (Fig. 5B). On the dorsal side, the head cavity is occupied by voluminous folds of the pharynx (Fig. 5C). Each tentacle contains a coelomic cavity lined with a coelomic epithelium. The epithelial cells form outgrowths that extend into the cavity and that connect the lining of the coelom of 

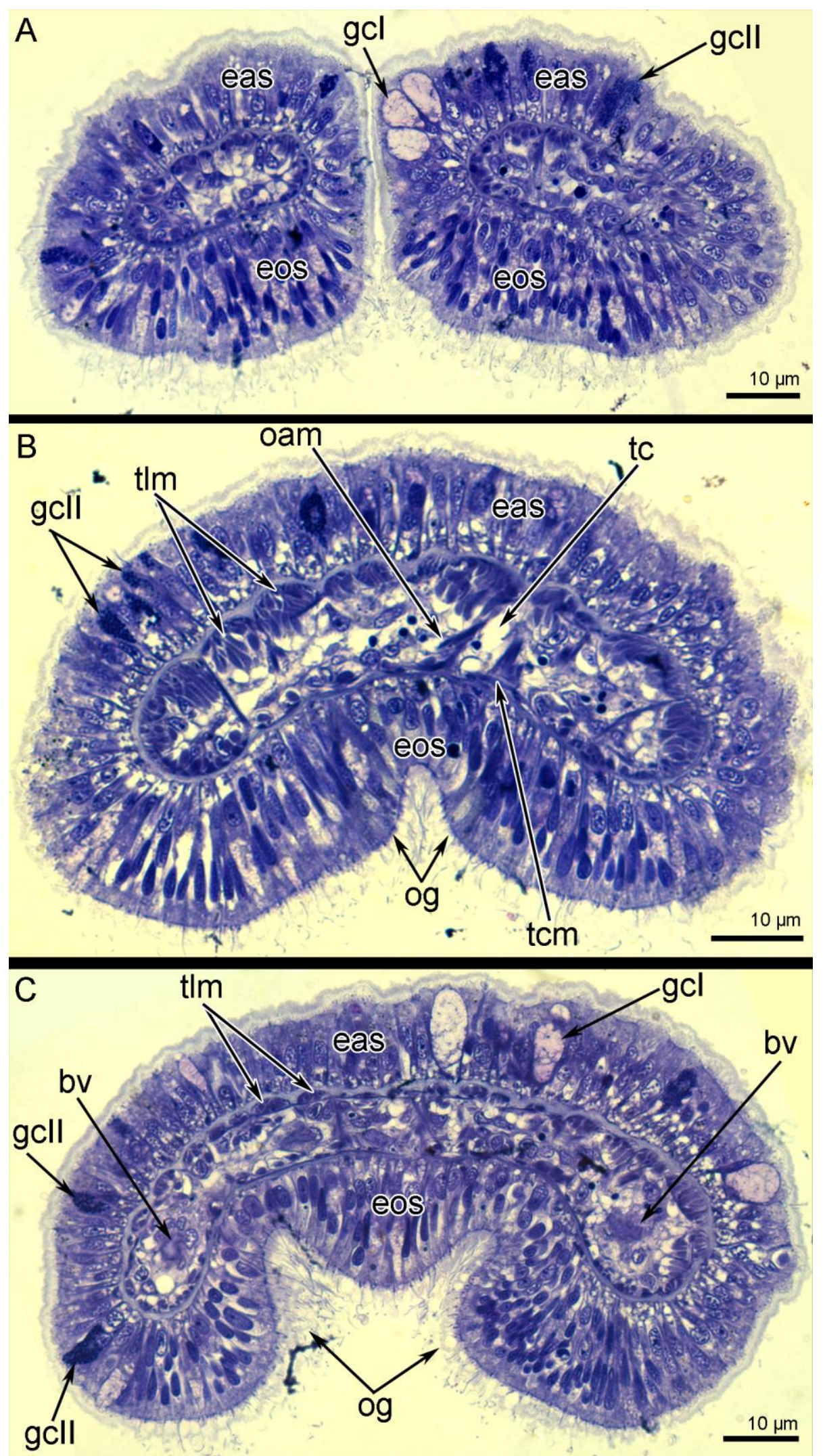

Figure 2. Organization of tentacles of Owenia borealis. Transverse semi-thin sections at different levels of tentacles. (A) Forked tip of tentacle. (B) Middle portion of tentacle. (C) Base of tentacle. Abbreviations: as - aboral side; bv - blood vessel; eas - epithelium of aboral side; eos - epithelium of oral side; gcl - gland cell of first type; gcll - gland cell of second type; oam - oral-aboral muscles; og - oral groove; tc - tentacle coelom; tlm - tentacle longitudinal muscles. 
the aboral and oral sides of the tentacles (Figs. 2, 3B). The coelomic lining is composed of myoepithelial cells that form the musculature of the tentacles and the wall of the blood vessel (Figs. 3A, B; 4D). The musculature of each tentacle includes longitudinal, circular, and oralaboral muscles (Figs. 2, 3). Circular muscles form a thin layer that is only present on the oral side of the tentacles (Figs. 2B, 3B). The strands of the longitudinal muscles are much thicker (due to an increased number of cells) on the aboral than on the oral side of the tentacle (Fig. 2B; 3B). Cells of all types of muscles are attached to the extracellular matrix via hemidesmosomes (Fig. 3B). The head cavity is lined by coelomic epithelium, which is formed by different types of cells (Fig. 6B, C). Most of these cells are the myoepithelial monociliated cells that form the longitudinal musculature of the head (Fig. 6A, C). Each myoepithelial monociliated cell bears one long cilium, at the base of which the basal body and accessory centriole are located (Fig. 6C). These cells contact each other via apical adhering junctions, which are usually located on the thin apical projections (Fig. 6C). A large nucleus occupies the apical portion of the cell, whereas myofilaments extend into the basal portion of the cell. Myofilaments are organized as in cross-striated muscles: in cross section, there are light and dense areas that correspond to aggregations of actin and myosin filaments (Fig. 6C). The cells are anchored to the basal lamina by hemidesmosomes (Fig. 6C). The myoepithelial monociliated cells of the coelomic lining form the walls of blood vessels of the head (Fig. 6D). These cells contain a few basal myofilaments that extend longitudinally (Fig. 6D). Portions of the coelomic lining are formed by a typical peritoneal coelothelium that covers the longitudinal and circular musculature (Fig. 6B). The peritoneal cells lack myofilaments; they are attached to the basal lamina between muscle cells. Peritoneal cells are connected to each other and to the muscle cells by adhering junctions (Fig. 6B).

Blood vessels. Three-dimensional modelling revealed that the ventral and dorsal blood vessels give rise to numerous blood vessels in the head and tentacles (Fig. 5D). At the border between the first trunk segment and the head, the ventral blood vessel splits into two lateral efferent branches, which give rise to two prominent lateral blood plexuses (Fig. 5D). The 

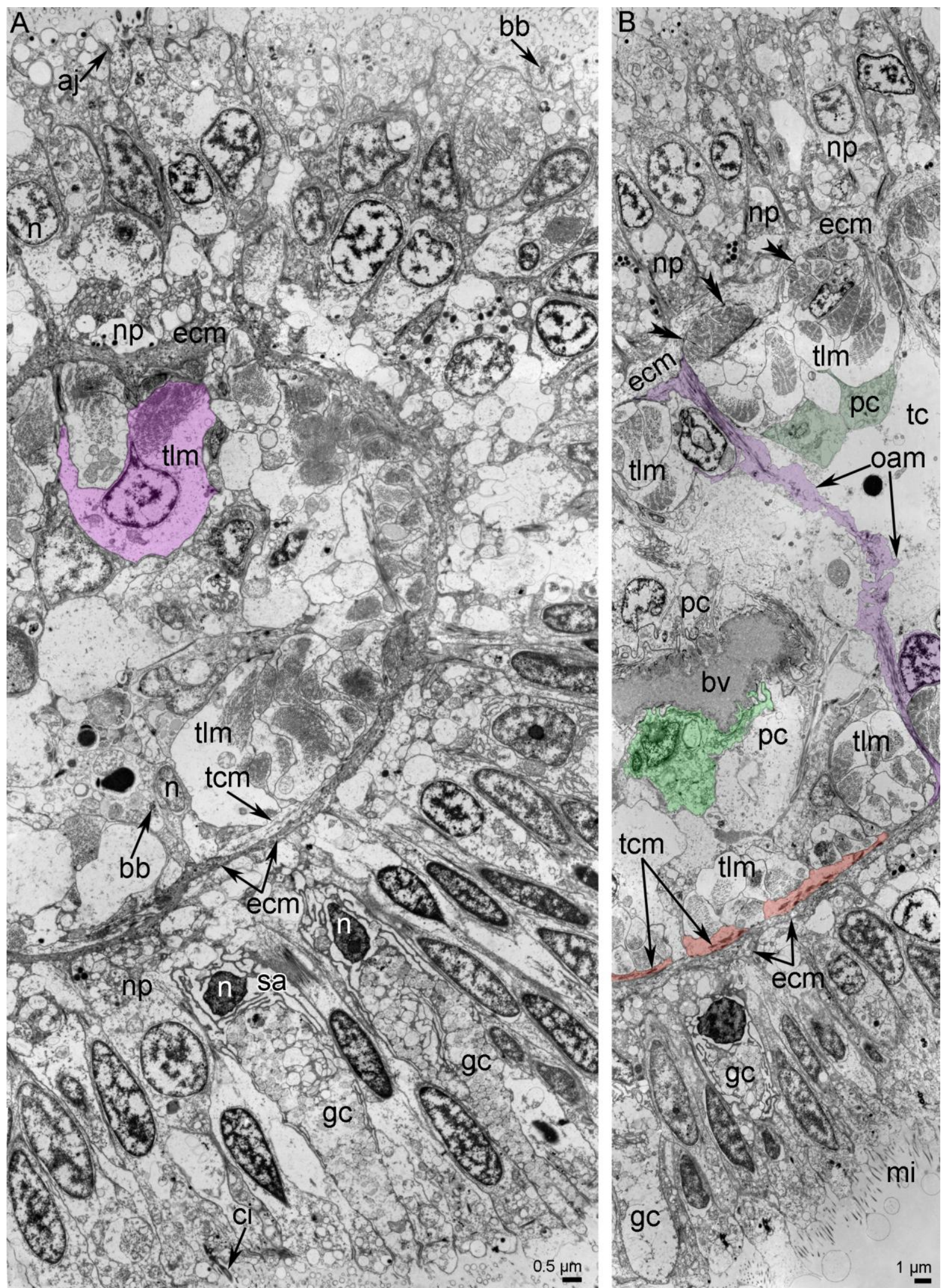

Figure 3. Details of tentacle ultrastructure of Owenia borealis (TEM). (A) General view of epithelia and coelomic cavity of tentacle. Cell of longitudinal muscle is shown in pink. (B) Different muscles of tentacle: oral-aboral muscle is shown in violet, tentacle cross muscles are shown in orange. Peritoneal cells, which cover longitudinal muscles, are shown in dark green. Cell, which includes into wall of blood vessel, is shown in light green. Hemidesmosomes are indicated by double arrowheads. Abbreviations: aj - adherence junction; bb - basal body; bv - blood vessel; ci - cilium; ecm extracellular matrix; gc - gland cell; $\mathrm{n}$ - nucleus; $\mathrm{np}$ - neuropil; oam - oral-aboral muscle; $\mathrm{pc}$ peritoneal cells; sa - secretory area of the gland cell; tcm - tentacle circular muscles; tlm - tentacle longitudinal muscles. 
255

256

257

258

259

260

261

262

263

264

265

266

267

268

269

270

271

272

273

274

275

276

277

dorsal blood vessel splits into two lateral afferent vessels at the middle of the head (Fig. 5D).

In each tentacle, there are three longitudinal blood vessels that are connected to each other (Fig. 5E). Together, they form the tentacular blood plexus.

Myoepithelial cells form the wall of blood vessels (Figs. 3B; 4D). The basal parts of these cells bear myofilaments and form numerous plasmatic projections, which extend into the lumen of the vessel (Fig. 4D).

\section{Neural elements of the head}

Anatomy. The head contains the main elements of the nervous system: the nerve center as a medullary commissure, two circumesophageal connectives with a pair of lateral medullary cords with a single commissure in between, the circumoral nerve ring, two ventrolateral roots of the circumoral nerve ring, and dorsal circular neurites that from a nerve net of the collar fold (Figs. 7A, B; 8A, B). All other nerve elements, such as the ventral medular nerve cord and the dorsal and lateral neurite bundles, are located in the first and other chaetigers (Fig. $8 \mathrm{~A}, \mathrm{~B})$.

Immunocytochemistry. Many of the neurite bundles exhibit acetylated alpha-tubulin-like immunoreactivity (-lir) (Fig. 9A, C, F) and serotonin-lir (Figs. 7B, 9B, D, E). Interestingly, labelling with both serotonin and acetylated alpha-tubulin antibodies revealed that the anterior nerve center has two parts: an anterior and posterior part (Fig. 9E). Anti-acetylated alpha-tubulin antibody staining was less intense in the anterior part than in the posterior part of the nerve center (Figs. 9E). The intensity of anti-serotonin antibody staining, in contrast, was similar in the anterior and posterior parts of the nerve center, but an area between the anterior and posterior parts is formed by neurites that do not exhibit serotonin-lir (Fig. 9E).

As a medullary dorsal commissure, the nerve center gives rise to the aboral tentacular neurite bundles (Fig. 9A). Four or five thick neurite bundles extend into each tentacle, where they spilt into many thin neurites that run along the aboral side of the tentacles. Some of these 

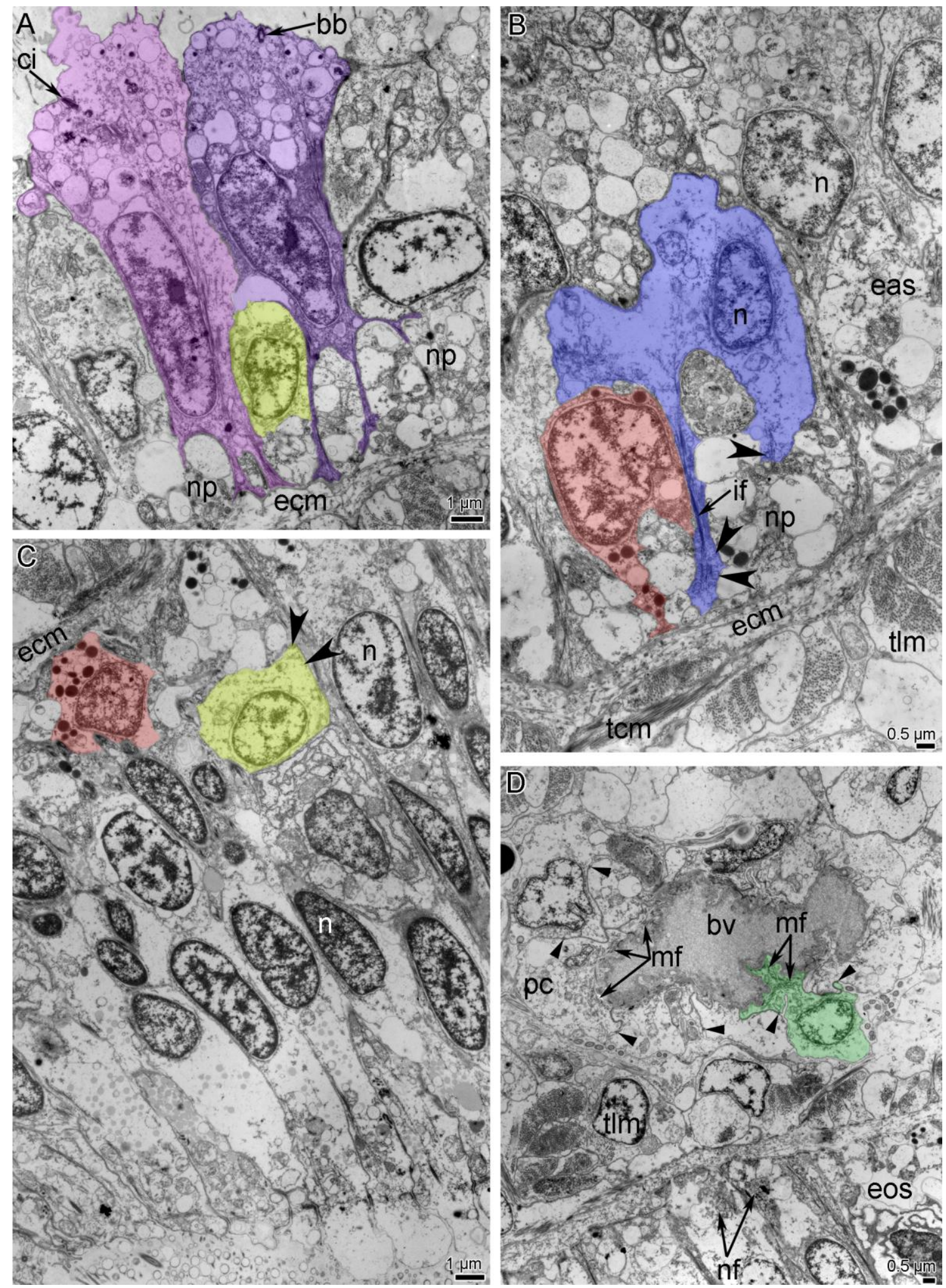

Figure 4. Ultrastructure of tentacle nerves and blood vessel of Owenia borealis (TEM). (A) Epithelium of aboral side: different types of cells. Two supportive cells are shown by different colors; perikaryon is shown in yellow. (B) The base of epithelium of aboral side: two types of glial cells are shown by red and blue. (C) Epithelium of oral side with perikaryon (yellow) and glial cell (red). Synaptic vesicles are indicated by concaved arrowheads. (D) Myoepithelial cells (green) of coelomic lining, which form the wall of blood vessel. Adherence junctions between cells are indicated by straight arrowheads. Abbreviations: bb - basal body; bv - blood vessel; ci - cilium; ecm - extracellular matrix; eas epithelium of aboral side; eos - epithelium of oral side; if - intermediate filaments; $\mathrm{mf}$ myofilaments; $\mathrm{n}$ - nucleus; $\mathrm{np}$ - neuropil; $\mathrm{pc}$ - peritoneal cells; $\mathrm{tcm}$ - tentacle circular muscles; $\mathrm{t} / \mathrm{m}$ tentacle longitudinal muscles. 
292 neurites exhibit serotonin-lir and are associated with epidermal sensory cells (Figs. 7A, B;

293 9B).

294 On the ventro-lateral sides of the head, the circumesophageal connectives that connect the

295 medullary dorsal commissure with the ventral nerve cord are simple, i.e., they do not divide

296 into dorsal and ventral roots before reaching the brain. Because the transition from the
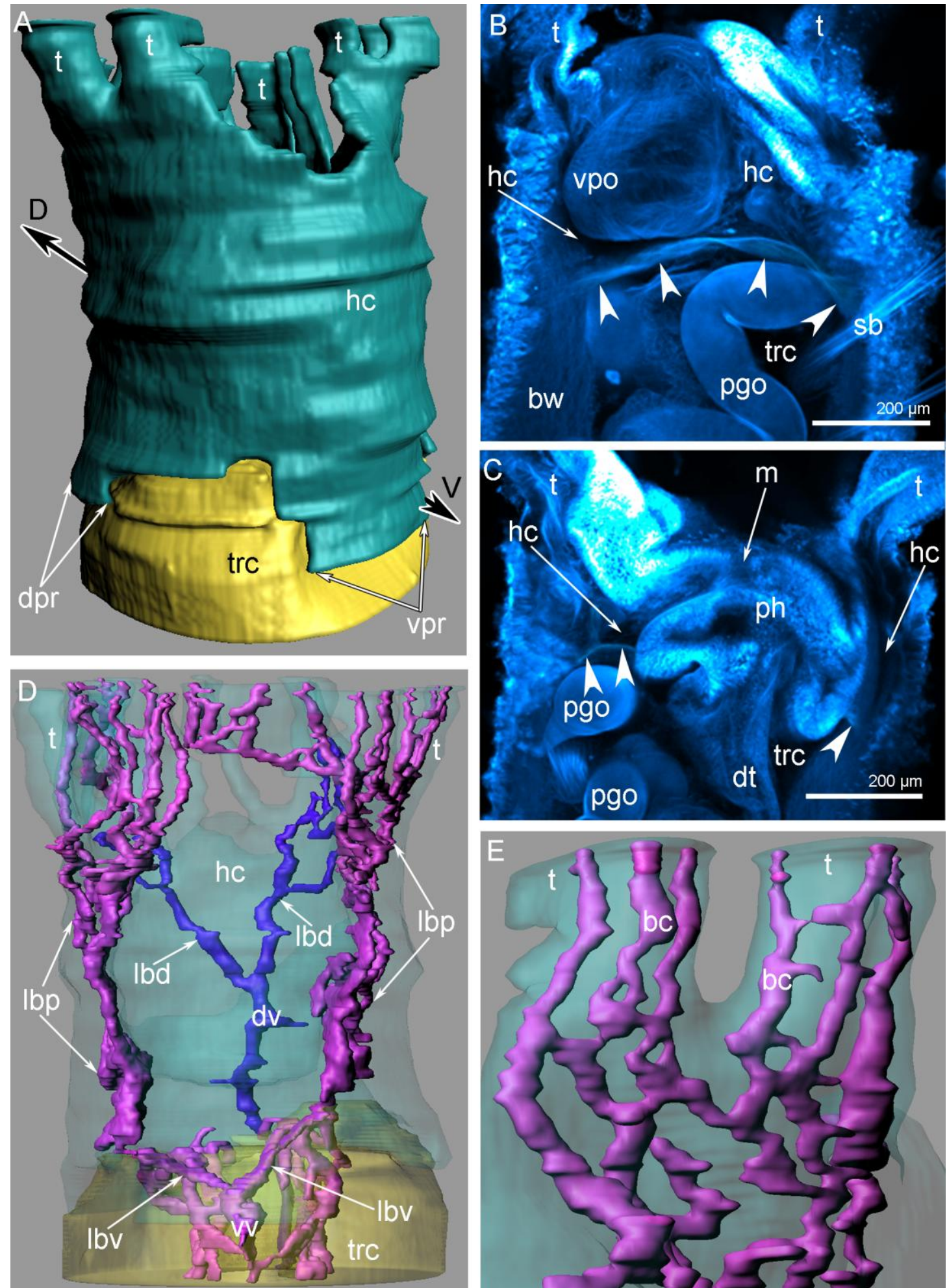
Figure 5. Organization of the coelom of the head of Owenia borealis. (A) Three-dimensional reconstruction of head (green) and trunk (yellow) coeloms. (B) Z-projection of head after staining with DAPI: dissepiment between head and trunk coeloms is indicated by arrowheads. (C) Zprojection of head and trunk cavity at sagittal optical section after staining with DAPI: dissepiment between head and trunk coeloms is indicated by arrowheads. (D) Three-dimensional reconstruction of blood vessels in head and part of trunk. Trunk and head coeloms are partly transparent. (E) Threedimensional reconstruction of blood capillaries in tentacles. Abbreviations: bc - blood capillary; bw body wall; dpr - dorsal protrusion; dt - digestive tube; dv - dorsal blood vessel; hc - head coelom; lbd - lateral branch of dorsal blood vessel; lbv - lateral branch of ventral blood vessel; lbp - lateral blood plexus; $\mathrm{m}$ - mouth; pgo - parapodial glandular organ; ph - parynx; $\mathrm{t}$ - tentacle; sb - setae bundle; trc - trunk coelom; vpo - ventral pharyngeal organ; vpr - ventral protrusion; vv - ventral blood vessel.

medullary dorsal commissure to the circumesophageal connectives is diffuse (Fig. 10A), it is

impossible to say where one ends and the other begins.

The circumesophageal connectives give rise to two ventro-lateral medullar nerve cords that

fuse together at the border between the head and the first chaetiger (Figs. 8A, 10A). Each connect the outer and inner nerve rings (Fig. 9C-F). The inner nerve ring gives rise to a few thin neurites that extend along the oral side of the tentacles (Fig. 9A).

On the ventral side of the body, two ventro-lateral medular cords are connected via a single, thin commissure (Figs. 7A,B; 9E, F; 10C). Each ventro-lateral medular cord forms several dorsal neurite bundles that fuse together on the dorsal side to form a nerve plexus (Fig. 10B, C). Several thin neurites extend along the dorsal side of the body (Fig. 10C). Thick lateral nerve tracts extend from the head region along both lateral sides of the body (Fig. 10D). Above the neuropodium of each segment, these nerve tracts form prominent varicoses (Fig. 10C). The medular ventral nerve cord consists of two pairs of nerve tracts: left and right (Fig. 10B). In each pair, prominent thick central and thin peripheral zones can be distinguished (Fig. 10C).

Histology and ultastructure. In the head, all nerve elements are located basiepidermally: perikarya and neurite bundles are located between the somata of the epidermal cells and the layer of the extracellular matrix (Figs. 7C, D; 11A, B). As a consequence, each nerve element has a stratified structure, in which the cellular components form three layers, i.e., the upper, 
332 epithelial cells. The middle layer is formed by the perikarya of the neurons. The lower layer

333 is formed by nerve projections and projections of epithelial cells (Figs. 7C, D; 11A, B).
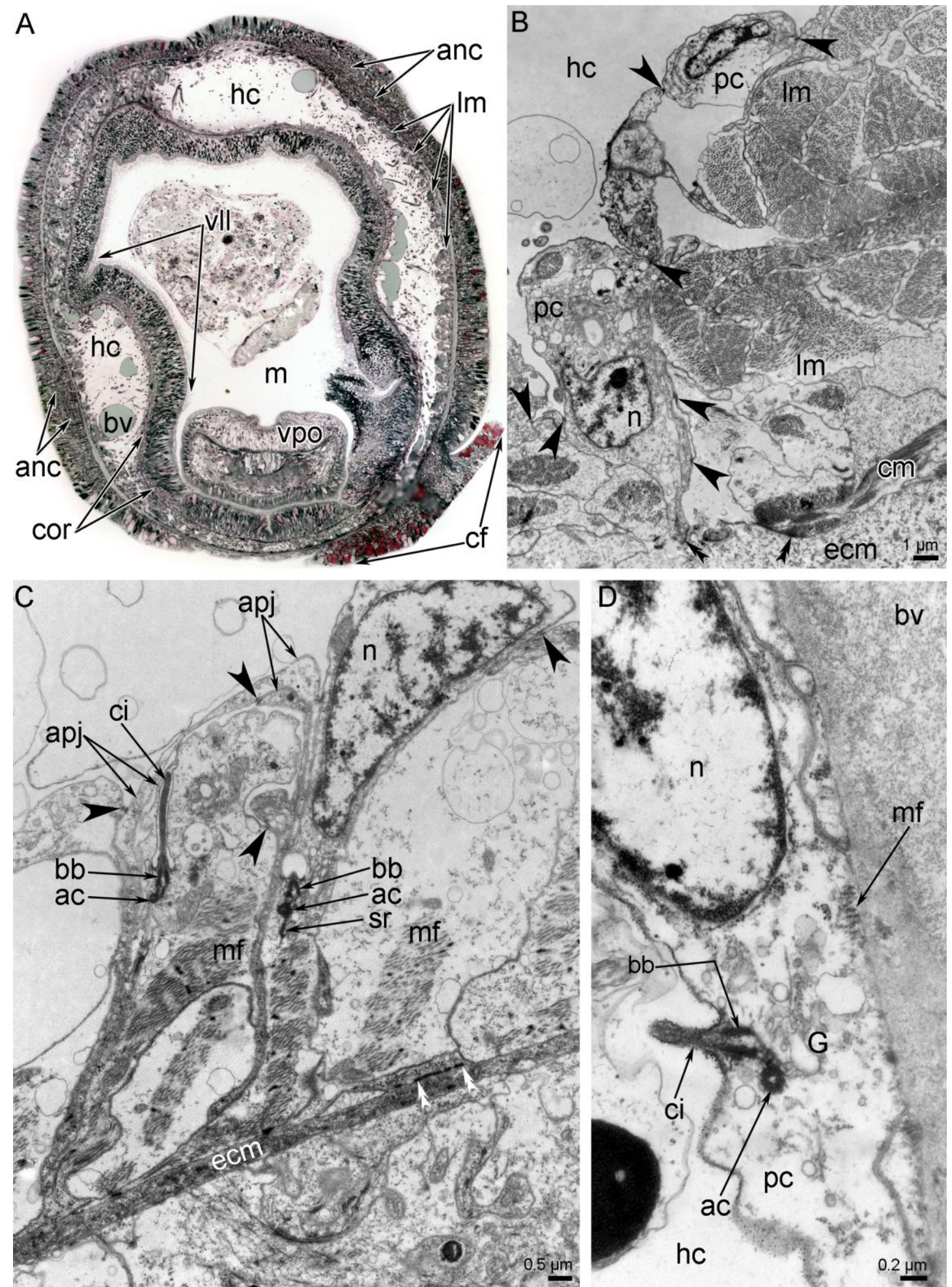

Figure 6. Histology and ultrastructure of the coelom of the head of Owenia borealis. (A) Semi-thin transverse section of the head: the spacious head coelom is visible. (B) Ultrastructure of a part of coelomic lining, which is formed by alternating peritoneal and myoepithelial cells. Adherence junctions between cells are indicated by arrowheads. Hemidesmosomes are indicated by double arrowheads. (C) Coelomic lining, which is formed by monociliated myoepithelial cells. Adherence junctions between cells are indicated by arrowheads. Hemidesmosomes are indicated by double 
arrowheads. (D) A part of wall of blood vessel, which consists of monociliated myoepithelial cells. Abbreviations: ac - accessory centriole; anc - anterior nerve center; apj - adherence junction; bb basal body; bv - blood vessel; ci - cilium; cf - collar fold; cm - circular muscles; cor - circumoral nerve ring; ecm - extracellular matrix; G - golgi apparatus; hc - head coelom; Im - longitudinal muscle; $\mathrm{m}$ - moth; $\mathrm{mf}$ - myofilaments; $\mathrm{n}$ - nucleus; $\mathrm{pc}$ - peritoneal cell; $\mathrm{sr}$ - striated rootlet; vll ventrolateral lip; vpo - ventral pharyngeal organ.

As a medullary commissure, the nerve center lies at the tentacle base, in the outer epidermis of the head (Figs. 7C, 11A, B). The epithelium, which includes the nerve center, is up to $45 \mu \mathrm{m}$ in height (Figs. 7C, 11A). The neurite bundles, which make up the largest portion of the nerve center, form a layer that is up to $30 \mu \mathrm{m}$ thick (Fig. 7C). According to TEM, the epithelium, which contains the nerve center, is formed by monociliated cells and has a wide apical part and a narrow basal part that is transformed into a long thin process. The apical surface of the monociliated cells bears thin long microvilli, whose tips are electron dense (Fig. 11A). A thick layer of cuticle is located between the microvilli and cilia. The basal body and accessory centriole are located at the base of the cilium. The cytoplasm of the monociliated cells has many large vesicles and an electron-lucent content (Fig. 11A). Electron-dense bundles of intermediate filaments extend into the apical cytoplasm, where they fuse with each other and occupy the long basal projection; the latter projection extends between the neurite bundles of the nerve center and adheres to the basal lamina via hemidesmosomes (Fig. 11A). The epithelium of the nerve center contains many gland cells of two types, which are similar to those of gland cells in the tentacle epithelium: cells of first type contain large vesicles with mucous content and cells of send type are filled with small dense granules (Fig. 7C). In the nerve center, perikarya are scattered between the somata of the epithelial cells, above the neuropil (Fig. 11A). These perikarya are small (diameter $\sim 5$ $\mu \mathrm{m})($ Fig. 12A). The nucleus in these cells has an irregular shape, lacks a nucleolus, has electron-lucent karyoplasm, and contains large aggregations of heterochromatin in the centre (Fig. 12A). The cytoplasm of the perikarya contains many synaptic vesicles that differ in diameter and content. The cytoplasm also contains mitochondria that are small, not abundant, and have an electron-dense matrix (Fig. 12A). The neuropil, which is formed by numerous neurites, is located between the perikarya and the extracellular matrix. In the nerve center, 
two components of the neuropil can be distinguished at the ultrastructural level. The first component is the upper portion of the neuropil, which is mostly formed by circular neurites that are cut longitudinally in transverse sections of the nerve center (Fig. 11A). The second component is the lower layer, which is mostly formed by longitudinal neurites that are cut transversally in transverse sections of the nerve center (Fig. 11A). In the nerve center, the neuropil consists of neurites that differ in structure. Some of these neurites have small diameters and electron-dense cytoplasm, which regularly form wide varicoses with electronlucent cytoplasm. The cytoplasm of these small neurites contains synaptic vesicles with electron-dense content and with content of intermediate electron density (Fig. 12A, B). Other neurites of the neuropil usually have large diameters and electron-lucent cytoplasm, and contain dense-core synaptic vesicles and vesicles with electron-lucent content (Fig. 12B). In addition to these two types of neurites, the neuropil contains projections of cells that contain ovoid electron-dense granules (Fig. 12A, B).

\section{Discussion}

In the current research, we used TEM and immunocytochemistry coupled with CLSM to study the anatomy and ultra-anatomy of the anterior nerve center. We report the absence of a brain-like structure in $O$. borealis. We also used histology, TEM, SEM, and 3D modelling to examine the organization of the organ system of the tentacle crown of $O$. borealis with the goal of gaining insight into the evolution of Bilateria nervous system and feeding apparatuses.

\section{The stratified neuroepithelium of $\boldsymbol{O}$. borealis as a trait of the bilaterian anterior nerve} center

The supraesophageal ganglion, or brain, is considered to comprise a compact central mass of neuropil surrounded by a cell cortex (22). Our study revealed the absence of a ganglionic organization of the anterior nerve center in $O$. borealis. In $O$. borealis, serotonin-lir somata do not form a compact cell cortex, and tubulin-lir neurite bundles do not form a swelling 

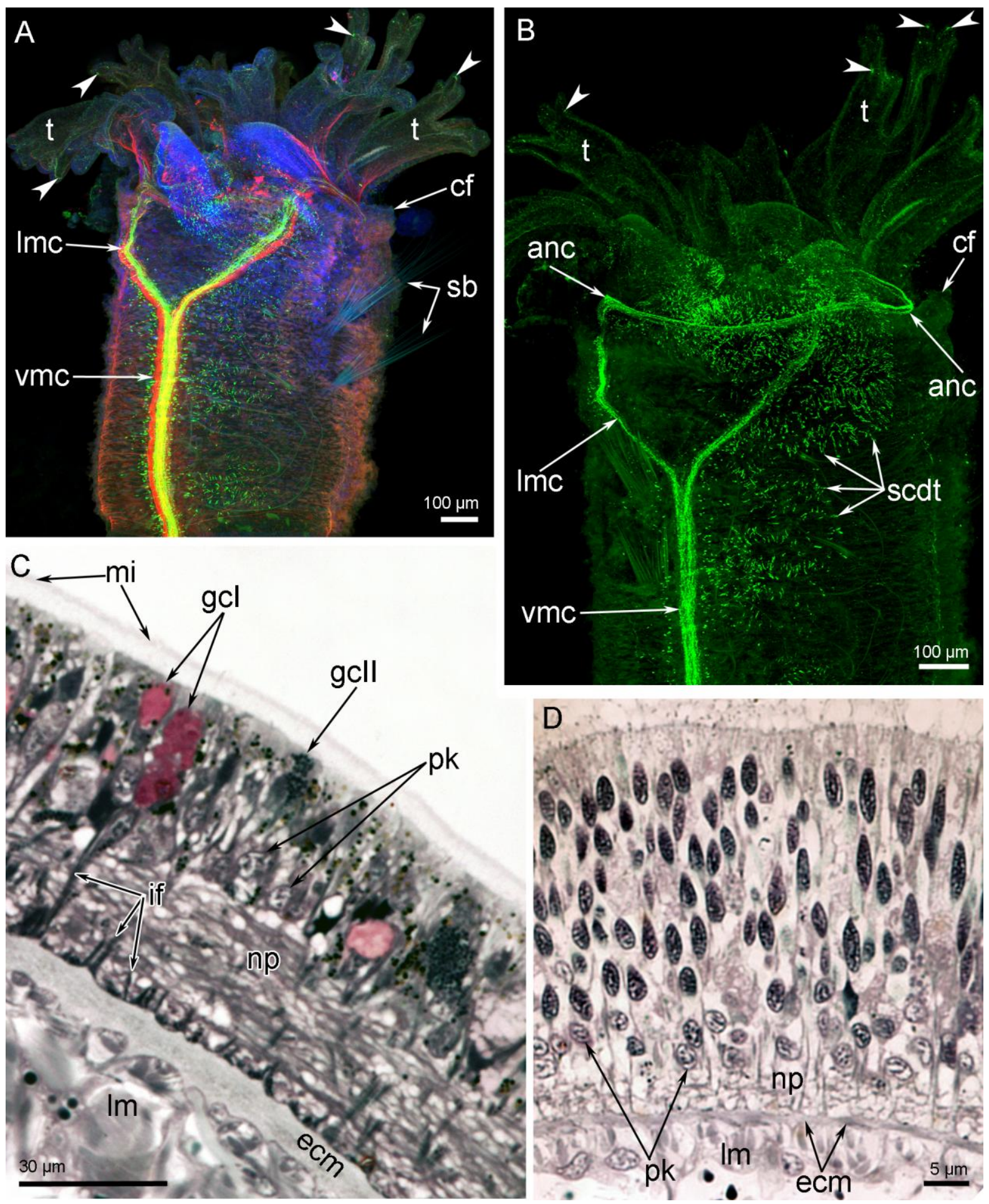

Figure 7. Organization of the nervous system of the head of Owenia borealis. (A) General anatomy of the nervous system viewed from the ventral side: Z-projection after double immunostaining against acetylated alpha-tubulin (red) and serotonin (green) and staining with DAPI (blue). (B) Serotonin-lir nerve elements of the head viewed from the ventral side; Z-projection after immunostaining against serotonin (green). Some serotonin-lir cells in the epithelium of tentacles are indicated by arrowheads. (C) Semi-thin transverse section of the anterior nerve center. (D) Semi-thin transverse section of the circumoral nerve ring. Abbreviations: anc - anterior nerve center; cf - collar fold; ecm - extracellular matrix; gcl - gland cell of first type; gcll - gland cell of first type; if - intermediated 
A

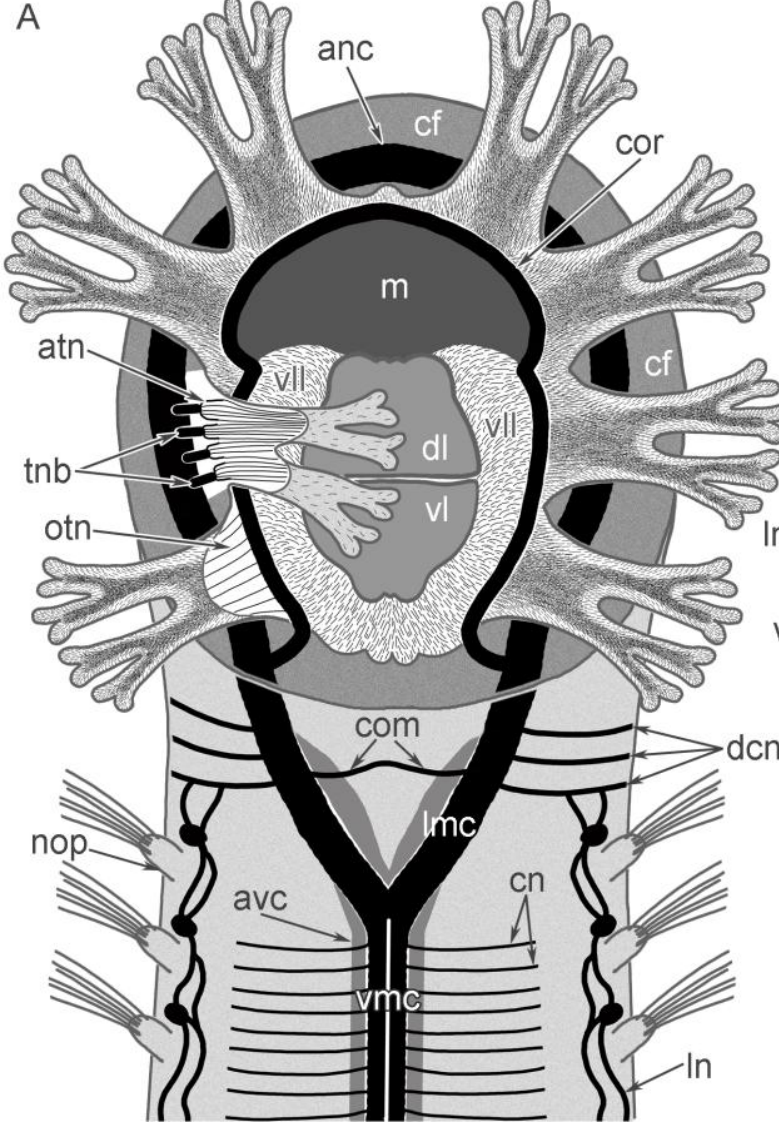

B

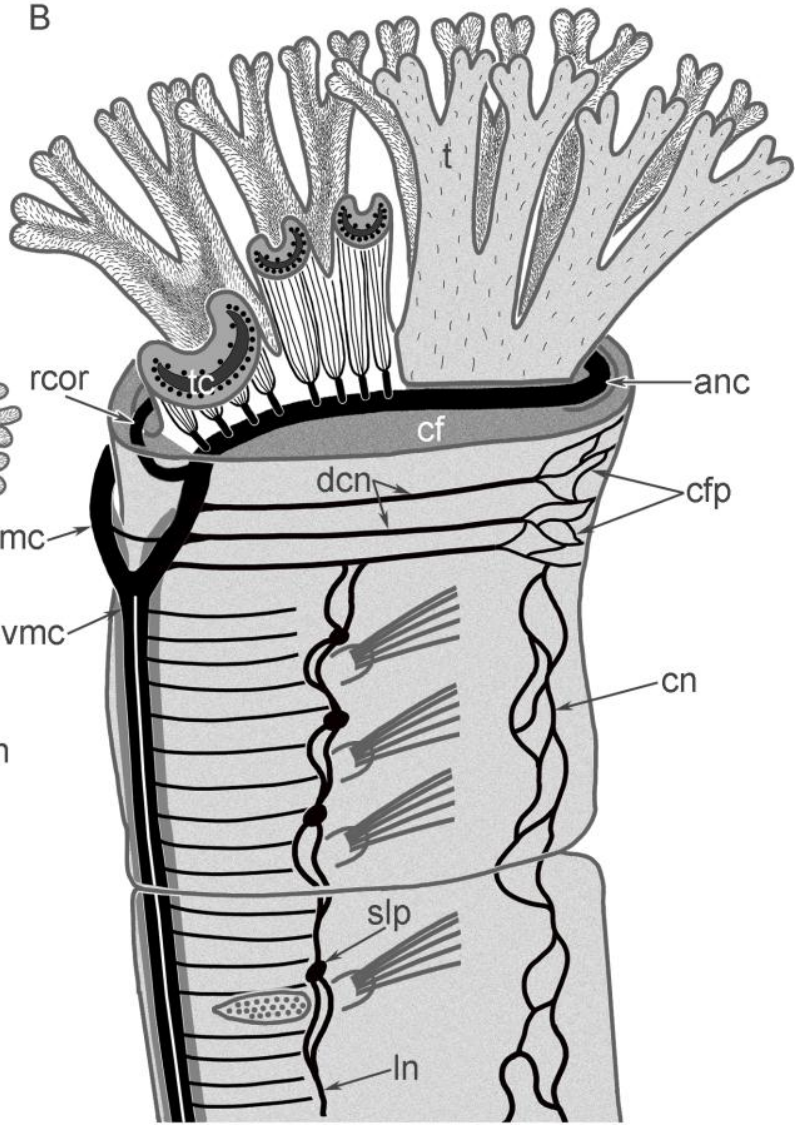

Figure 8. Schemes of the nervous system organization of the anterior body part of Owenia borealis. All nerve elements are shown in black. (A) Ventral view. (B) Lateral view. Abbreviations: anc anterior nerve center; atn - aboral tentacle nerves; avc - additional ventral cord; cf - collar fold; cfp - collar fold dorsal nerve plexus; cn - cross nerve; com - ventral commissure; cor - circumoral nerve ring; dcn - dorsal cross nerve; dl - dorsal lip of the ventral pharyngeal organ; dn - dorsal neurites; Idn - laterodorsal nerve; Imc - lateral medullary cord; m - mouth; nep - neuropodia; nop notopodia; otn - oral tentacle nerves; pbr - posterior portion of the brain; ph - pharynx; rcor - root of circumoral nerve ring; slp - serotonin-lir perikarya; stn - serotonin-lir neurites of tentacles; $t$ tentacle; tbn - tentacle neurite bundle; $v$ - ventral lip of the ventral pharyngeal organ; vmc - ventral medullary cord.

bundles. It follows that the anterior nerve center of $O$. borealis could be termed a "medullary

dorsal commissure". The medullary dorsal commissure has also been documented in adults of

clade can be termed the "medullary dorsal commissure".

In a previous study, electron microscopy revealed that $O$. borealis has a stratified 
neuroepithelium has also been described based on TEM in O. fusiformis and G. oculata (see Fig $8 \mathrm{~A}$ in (15) and Fig 3D in (13)). We therefore suggest that all oweniids probably have the dorsal medullary commissure, which is organized as a stratified neuroepithelium.

The stratified neuroepithelium in $O$. borealis consists of three layers: somata of glial cells, perykaria of neurons, and the neuropil. A similar organization can be found in in protostomes such as brachiopods (57), phoronids (38,58), oweniid annelids (this study; (15)), and echiurid annelids (Temereva, Kuznetsov, personal observation), and in priapulids (29). The organization can also be found in deuterostomes such as enteropneust hemichordates (29) and echinoderms (59), as well as in the sister group to all remaining bilateria, the nemetodermatid acoelomorph (see Fig. 5F' in (60)). Thus, a stratified neuroepithelium may represent the ancestral trait of the anterior nerve center in all bilaterians. That possibility is consistent with earlier suggestions regarding the ancestral state of the intraepidermal and non-ganglionic anterior nerve center of bilaterians $(7,15,23-29)$.

\section{The non-specialized tentacle crown in oweniids}

Oweniids primarily feed on the surfaces of substrates, and those species with a tentacle crown also use it in suspension feeding (61). The degree of specialization in feeding probably determines the architecture of the tentacle crown, which may differ in number of tentacles, crown length, ramification from the base, rate of branching, and the shape of grooves that conduct particles from the tentacle tips to the mouth (62-66). The tentacle crown of $O$. borealis branches from its base and is formed by five tentacles on the left and right sides of the head. All tentacles consist of four branches, except the most ventral pair, which consist of two branches (Fig. 1A). Oral tentacle grooves in $O$. borealis are 50-60 um in diameter and are formed by fused tentacle branches. The tentacles are covered by a monociliated epithelium on both aboral and oral sides. Ciliation is denser on the oral side due to the columnar epidermal cells on the oral side. Taking into account all these traits, we 

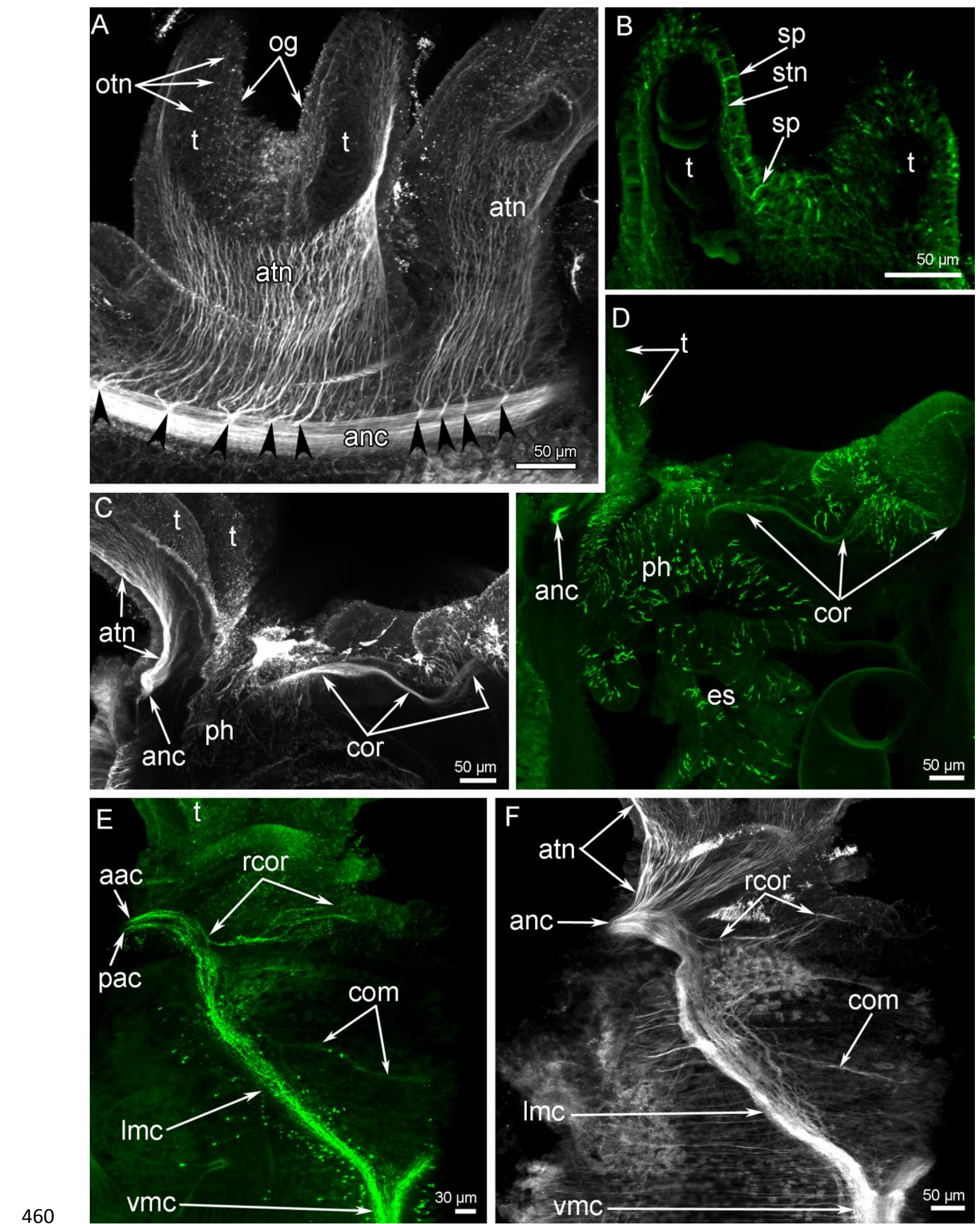

Figure 9. Details of innervation of tentacle crown and oral area in Owenia borealis. CLSM data: Zprojections after immunostaining against acetylated alpha-tubulin (grey) and serotonin (green). (A) The aboral side of tentacle base: several short thick nerves (arrowheads) extend from the anterior 
neurites in the epithelium of tentacle. (C) Central portion of the head: circumoral nerve ring is visible. (D) Central portion the head: serotonin-lir neurites are visible in the circumoral nerve ring. The epithelium of pharynx contains numerous serotonin-lir cells. (E) A portion of the head viewed from the ventral side. There are anterior and posterior portions of the anterior nerve center. Right ventrolateral root of the circumoral nerve ring and ventral commissure are visible. (F) Right portion of the head viewed from the ventral side. Abbreviations: aac - anterior portion of the anterior nerve center; anc - anterior nerve center; atn - aboral tentacle nerves; com - ventral commissure; cor circumoral nerve ring; es - esophagus; Imc - lateral medullary cord; og - oral groove; otn - oral tentacle nerves; pac - posterior portion of the the anterior nerve center; ph - pharynx; rcor - root of circumoral nerve ring; sp - serotonin-lir perikarya; stn - serotonin-lir neurites of tentacles; $t$ tentacle; vmc - ventral medullary cord.

Innervation of the tentacle crown. Recent studies have shown that the nervous system anatomy of the tentacle crown of the lophophorates, which are highly specialized filter feeders, has a characteristic organization. The tentacle crown of the lophophorates contains two nerve centers and two circular nerves that give rise to the intertentacular nerves that innervate two adjacent tentacles $(42,58)$. Together, all of these neural structures may represent a ground pattern of the tentacle crown innervation of the phoronid-like ancestor of lophophorates (51). Interestingly, at the base of the tentacle crown of the annelid $O$. borealis, we documented both the external circular nerve (which is known in other oweniids $(12,13,15)$, and the complete internal circular nerve (which is only partly represented in Galathowenia oculata (13). Other features of the tentacle crown innervation pattern that are present in the highly specialized filter feeders are absent in $O$. borealis. For example, $O$. borealis lacks a ganglionic nerve center (see the Discussion above about the stratified neuroepithelium) and lacks intertentacular nerves, i.e., each tentacle is independently innervated. The presence of intertentacular nerves, which innervate adjacent tentacles, is an important character filter-feeders such as lophophorates (46). Among annelids, the highly specialized filter feeders, the sabellids, have these nerves (61).

Musculature of the tentacle crown. The muscles of the tentacle crown in $O$. borealis are mainly represented by longitudinal bundles, most of which are located on the crown's aboral side (Figs. 2B, C, 3B). Contraction of the longitudinal muscles pulls the tentacles outward and opens the tentacle crown. The longitudinal musculature in $O$. borealis thereby helps the tentacle crown to collect particles that are suspended in the water column or that 

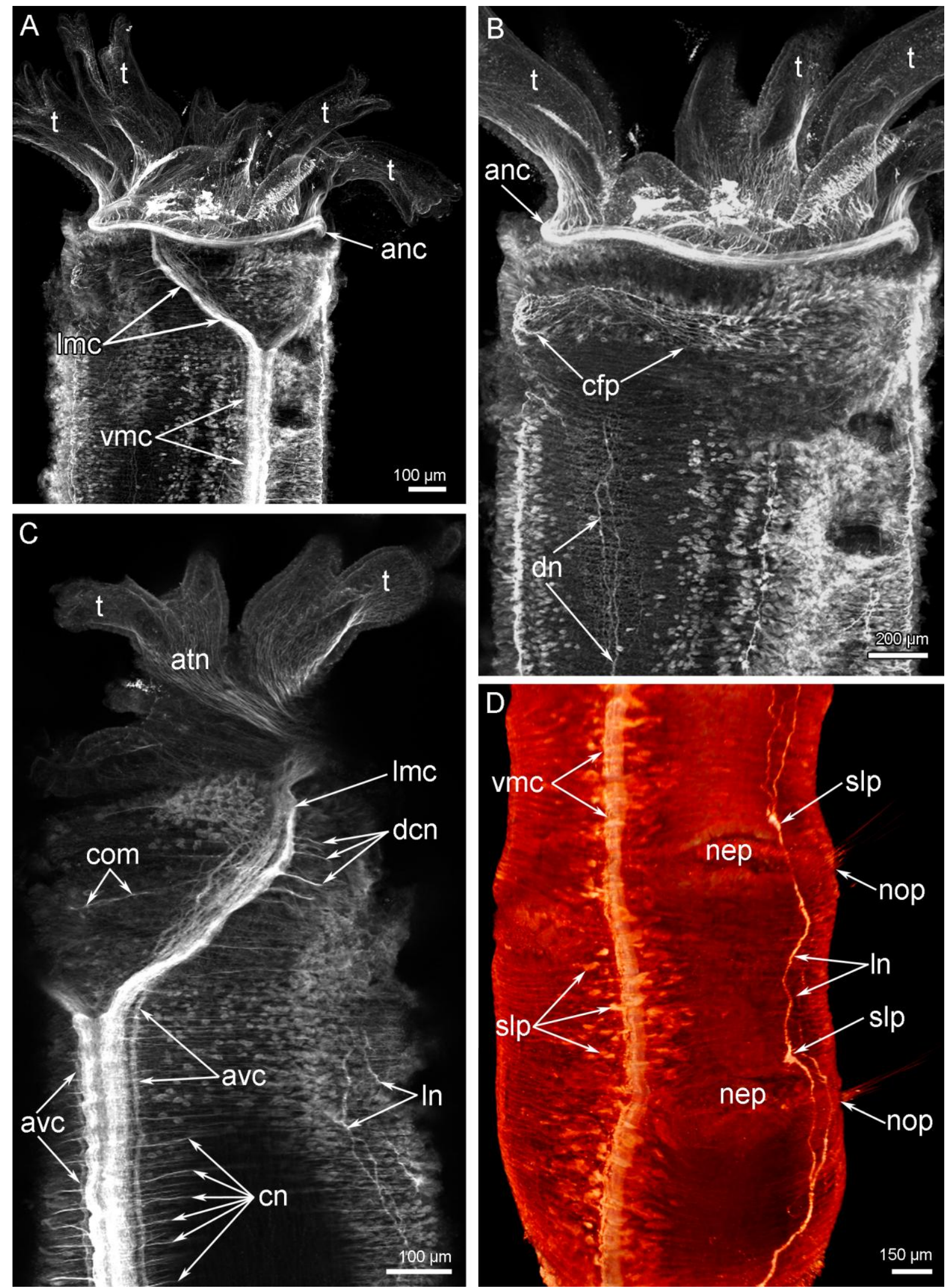

Figure 10. Details of the nerve element location in the head and adjacent segments of Owenia borealis. CLSM data: Z-projections $(A-C)$ and volume rendering (D) after immunostaining against acetylated alpha-tubulin (grey and orange). (A) A head with tentacle crown viewed from the ventral side. (B) A head with some tentacles viewed from the dorsal side. (C) Left portion of the head viewed 
from the ventral side. (D) A portion of the body near the head viewed from the left. Abbreviations: anc - anterior nerve center; atn - aboral tentacle nerves; avc - additional ventral cord; com - ventral commissure; cfp - collar fold dorsal nerve plexus; cn - cross nerve; dcn - dorsal cross nerve; dn dorsal neurites; Imc - lateral medullary cord; In - lateral nerve; nep - neuropodia; nop - notopodia; slp - serotonin-like lateral perikarya; $\mathrm{t}$ - tentacle; vmc - ventral medullary cord.

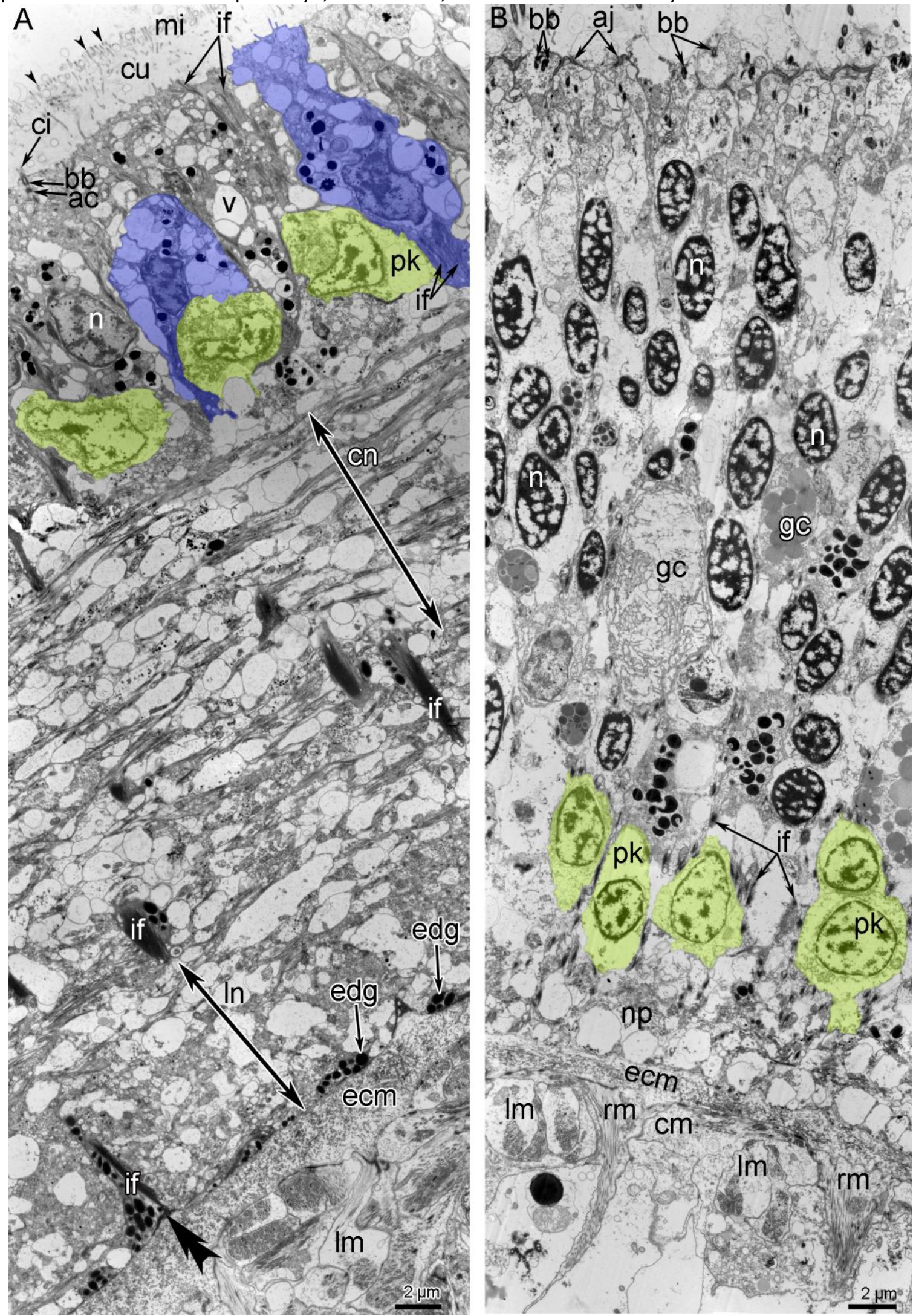

Figure 11. Ultrastructure of head nerve elements in Owenia borealis. Ultra-thin transverse sections. (A) A portion of the ring-shaped anterior nerve center. (B) A portion of the circumoral nerve ring. Supportive cells (= radial glial cells) are shown in blue; perikarya are shown in yellow. Hemidesmosome is indicated by double arrowhead. Dense tips of microvilli are indicated by 
arrowheads. Abbreviations: ac - accessory centriole; aj - adherence junction; bb - basal body; $c n$ cross extended neurites; cu - cuticle; ecm - extracellular matrix; edg - electron dense granules; gc gland cell; if - intermediate filaments; In - longitudinally extended neurites; mi - microvilli; $\mathrm{n}-$

nucleus; $\mathrm{np}$ - neuropil; pk - perikaryon.
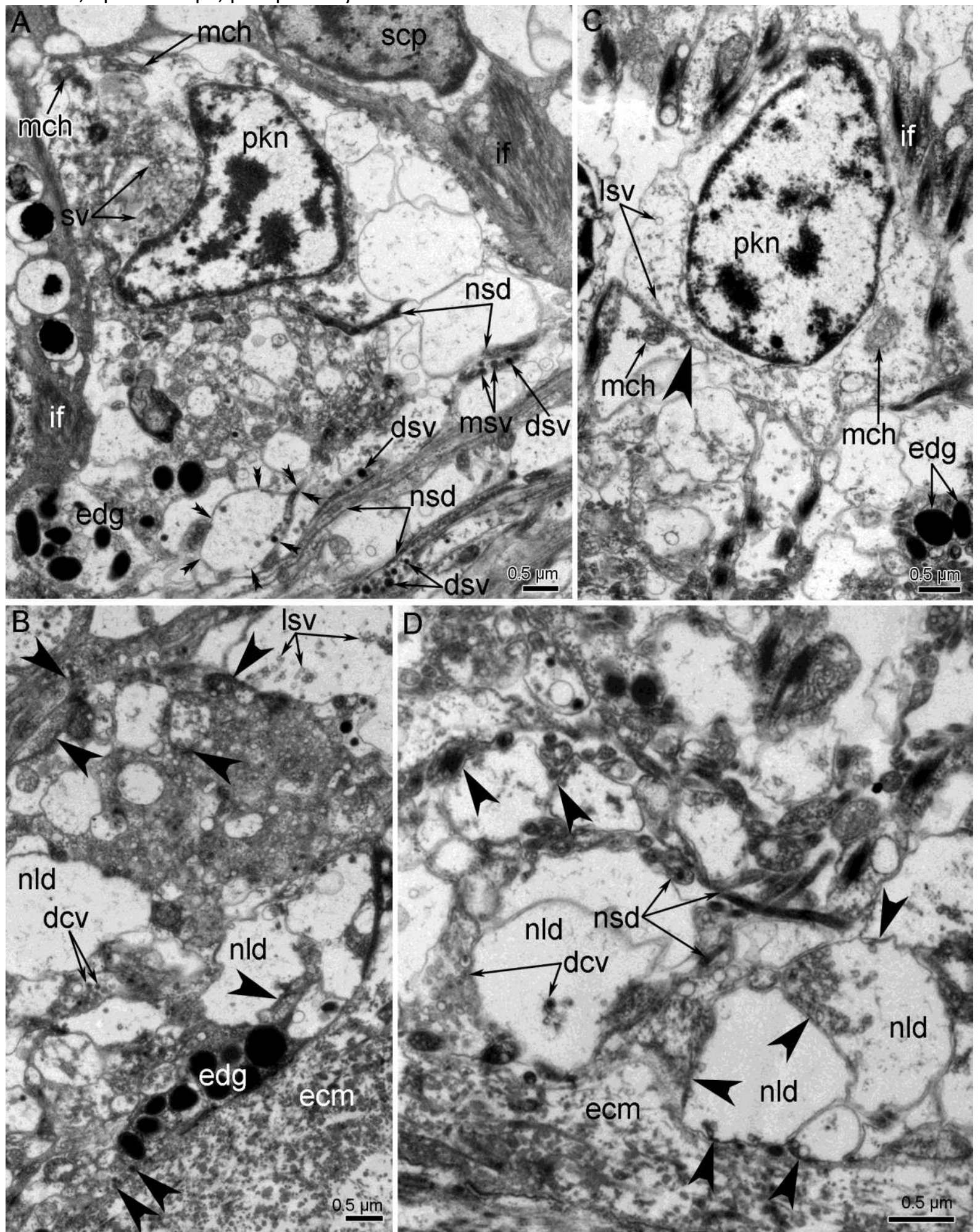

Figure 12. Ultrastructural details of the anterior nerve center $(A, B)$ and circumoral nerve ring $(C, D)$ of Owenia borealis. (A, C) Perikarya, which are surrounded by supportive cells and their projections. $(D, E)$ The basal portions of neuropil. Synaptic-like structures, which are characterized by cell membrane density and by synaptic vesicle concentration, are indicated by arrowheads. Abbreviations: dcv - dense-core synaptic vesicle; dsv - dense synaptic vesicles; ecm - extracellular matrix; edg - electron dense granules; if - intermediate filaments; Isv - light synaptic vesicle; msv synaptic vesicle with content of middle electron density; nld - neurite of large diameter; nsd neurite of small diameter; pkn - nucleus of perikaryon; scp - supportive cell; sv - synaptic vesicle. 
oral side of the tentacles (Fig. 3A). In those annelids that are specialized filter feeders, the outward expansion of the fan of tentacles also occurs due to the contraction of the aboral longitudinal muscles. Those filter feeders, however, also have a cartilaginous skeleton as well as muscles at the base of the tentacular crown that serve as antagonists of the aboral longitudinal muscles, i.e., that enable the organism to withdraw the tentacles and move the captured particles to the mouth (70).

In the tentacles of $O$. borealis, the circular muscle layer is very thin. Although this muscle layer may represent only short fragments of individual muscle filaments, we suspect that it represents a complete muscle ring (Fig. 2B, 3A). In the tentacles of the specialized filter feeders such as the lophophorates and annelids Sabellidae and Serpulidae, a complete reduction of the circular muscles occurs (70-73). That $O$. borealis apparently retains the circular muscles in the tentacles is consistent with the inference of a non-specialized mode of feeding.

\section{Coelomic lining of the tentacle crown. Four types of coelomic myoepithelium have} been described in echinoderms, various annelids, and lophophorates: simple, pseudostratified, bipartite pseudostratified, and stratified (74-77). The coelomic epithelium in O. borealis is intermediate between the simple and the pseudostratified myoepithelium. The pseudostratified myoepithelium is known for echinoderms $(74,78)$, brachiopods $(77,79)$, phoronids $(58,72)$, and sedenterian and errantian annelids $(75,76)$. The cells of a pseudostratified myoepithelium are arranged in two rows: internal myoepithelial cells and external non-muscular epithelial cells (i.e., cells without myofilaments). In $O$. borealis, both rows of cells have myofilaments. The internal myoepithelial cells are mainly used for contraction, and their wide basal parts contain longitudinal or rarely circular myofilaments (Figs. 3, 6C). Because both types of cells in $O$. borealis are myoepithelial, the pseudostratified myoepithelium of $O$. borealis differs from the pseudostratified myoepithelium described by Rieger and Lombardi (74). We propose that the coelomic lining 
of the head and tentacles of $O$. borealis is intermediate between the simple and pseudostratified evolutionary stages of the coelomic epithelium of Bilateria.

The pseudostratified myoepithelium is considered to be associated with the basiepidermal nervous system: each myoepithelial cell receives a signal from neurotransmitters in the immediate vicinity of the neurons (75). Together, the pseudostratified myoepithelium and the basiepidermal nervous system in $O$. borealis have been recognized as plesiomorphic traits of the epithelia of the body wall in annelids $(15,26,27)$ and possibly in Spiralia (7). It follows that, on the one hand, the myoepithelium of the coelomic lining and the basi-epidermal nervous system co-evolved in Owenia. On the other hand, the myoepithelial cells of the coelom do not specialize in performing various functions, all cells carry myofilaments, and there is no typical pseudo-stratified myoepithelium.

To summarize this part of the Discussion, we observed the presence of a non-specialized tentacle crown in $O$. borealis and note that such crowns have also been observed in other oweniids with tentacles. The lack of a specialized tentacle crown corresponds with the structural elements of the nervous, muscular, coelomic, and circulatory systems. O. borealis lacks a dorsal brain but instead has an anterior nerve center in the form of the dorsal medullary commissure. There are no intertentacular nerves. Myoepithelial cells of the coelomic cavity are not specialized and represent an intermediate stage between simple and pseudostratified myoepithelium. The blood vessels form a complex network of capillaries in which the afferent and efferent vessels cannot be traced. The circular muscles remain, and there are no muscles that are antagonistic to the longitudinal muscles that open the tentacle crown.

\section{Evolution of the tentacle apparatuses}

578 It is assumed that various bilaterians, including annelids, cephalopods, onychophorans, echinoderms, and ascidians, have the same genetic program defining the coordinate grid of the various appendages or outgrowths of the body (80-82). At the same time, these 
581

582

583

584

585

586

587

588

589

590

591

592

593

594

595

596

597

598

599

600

601

602

603

604

605

606

appendages of the body are not homologous to each other, have different morphologies and perform completely different functions, for example, sensitive perception, nutrition, movement, etc. Interestingly, in different groups of the bilaterians, including annelids, the anterior outgrowths of the body specialized in parallel in capture of the food particles, the socalled tentacular apparatuses. Here, we consider the evolutionary trends of the organization of tentacular apparatus that are used for suspension and filter feeding.

$O$. borealis is one of the various annelids that has a tentacle apparatus or anterior appendages. A comparative analysis of the organization of tentacles in different groups of Bilateria reveals three main patterns of the tentacle specialization (Fig. 13). The first pattern is represented by highly specialized tentacles with a zonality of the epithelium that is co-localized with nerve tracts and muscle bundles. Specialized tentacles are found in some filter feeders including annelids in the families Serpullidae and Sabellidae (83), all lophophorates (Phoronida, Brachiopoda, and Bryozoa) (32,48,51), and Kamptozoans (=Entoprocta) (34,84). Specialized tentacles always have at least four zones: one oral, one aboral, and two lateral (Fig. 13A, B). Oral and lateral zones are heavily ciliated, whereas cilia are rare or even absent in the aboral zone. The aboral zone can undergo specialization involving the presence of additional skeletal structures and gland cells. These four zones are innervated by different nerve tracts. The epidermal zones and nerve tracts are co-localized. The muscle bundles are also colocalized with certain zones of tentacle. There are usually two muscular bundles, oral and aboral, which allow each tentacle to bend in two directions. Among all filter feeders, lophophorates have the most specialized tentacles, each of which bears eight zones: one frontal (oral), one abfrontal (aboral), two lateral, two laterofrontal, and two lateroabfrontal. Each of these zones is innervated by a specific nerve tract and has a specific function (51). The second pattern of tentacle organization is less specialized tentacles, which have at least two zones: heavy ciliated oral and less ciliated aboral. In the second pattern, the innervation of each zone is provided by a specific nerve tract. Less specialized tentacles occur in some 
annelids that are not specialized filter-feeders, i.e., the Fabriciidae and some Serpulidae $(71,83)$ (Fig. 13C). Although the information is scarce, fabriciids could be deposit and/ or suspension feeders $(61,83,85)$.

The third pattern of the tentacle organization is the non-specialized tentacles. Such tentacles lack zonality of the epidermis and co-localization of ciliary cells, nerve tracts, and muscular tracts (Fig. 13D, E). In these non-specialized tentacles, all sides are evenly ciliated. If present, ciliary zones are not co-localized with the nerve tracts or neurite bundles, which are evenly scattered in the tentacle. In the tentacles of the third type, muscle cells do not form bundles, and they are evenly distributed in the tentacle. The non-specialized tentacles can be found in oweniids (this study) and in some holothurians (86). Holothurians are deposit or suspension feeders and are able to attach deposited particles to tentacles due to the secretion of a glue by gland cells (87-89). The presence of many gland cells can be regarded as a kind of specialization but cannot be compared with the zonality of the highly specialized tentacles for filter-feeding.

If we assume that tentacles have been inherited from the LCBA, we can suggest the evolution of tentacle apparatuses from the non-specialized tentacles of deposit/suspension feeders to the highly specialized tentacles of the filter-feeders. This idea may be supported by data on morphology and diet of the Sabellidae, whose tentacles evolved from less specialized in the Fabriciidae to highly specialized in the Sabellidae (83). In the hypothetical order of tentacle evolution, $O$. borealis exhibits the least specialized tentacle apparatus, which can be regarded as ancestral for all bilaterians. On the other hand, we must keep in mind that tentacles may have appeared independently in different groups and evolved according to the mode of feeding. 

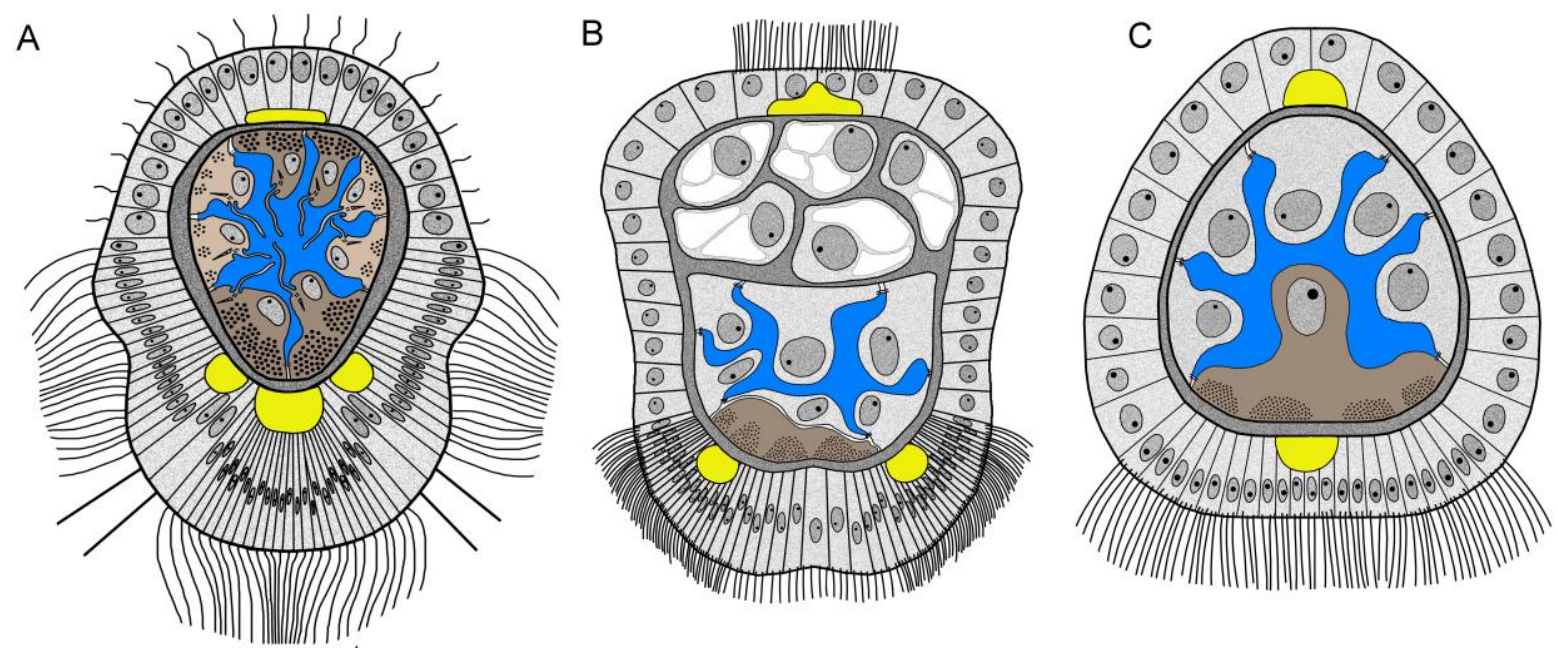

631

632

633

634

635

636

637

638

639

640

641

642

643

644

645

646

647

648

649

650
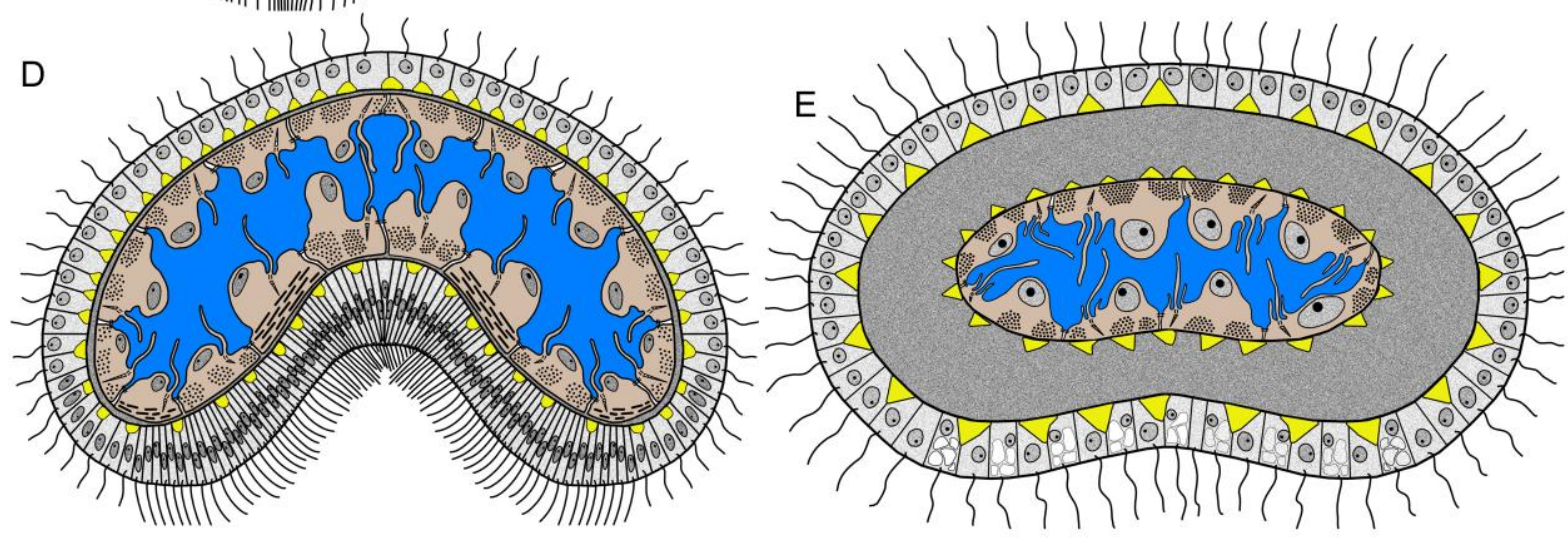

Figure 13. Schemes of transverse section of tentacles of different types. A-B: highly specialized tentacles; C - less specialized tentacle; D-E - non-specialized tentacles. (A) Generalized tentacle of lophophorates (based on 32,48,51). (B) Generalized tentacle of Serpullidae and Sabellidae (based on 83). (C) Generalized tentacle of Fabriciidae (based on 83) and serpulid Pomatoceros triqueter (based on 71). (D) Tentacle of Owenia borealis (this study). (E) Tentacle of holothuria Holothuria forskali (based on 86). Color code: yellow - nerve elements; blue - coelomic cavity; light broun myoepithelial cells; dark broun - mucle cells and myoepithelial cells with numerous myofilaments; dark grey - extracellulart matrix; light grey - epithelial cells.

\section{Conclusions}

In this report, we described the anatomy and ultra-anatomy of the tentacular crown of Owenia borealis. Because they belong to the clade of palaeoannelids $(3,5)$, the Oweniidae are important for studies of the morphological traits of annelid ancestors or even of bilaterian metazoan ancestors. In $O$. borealis, the anterior nerve center is represented by stratified neuroepithelium and consists of three layers: apical somata of the glial cells, perikarya of neurons, and the basal neuropil between the thin projections of the glial cells. Based on the available data on the structure of the various bilaterian lineages $(15,29,38,57-60)$, we suggest that the anterior nerve center of the last common ancestor of annelids and possibly of all bilaterian metazoans was a basiepidermal stratified neuroepithelium. After describing the 
651

652

653

654

655

656

657

658

659

660

661

662

663

664

665

666

667

668

669

670

671

672

673

674

675

676

677

678

679

680

681

682

683

684

685

686

687

architecture of the tentacle crown of $O$. borealis, and its innervation, musculature, blood

system, and coelomic myoepithelial lining, we compared the tentacle crown of $O$. borealis

with the tentacular apparatuses of the other bilaterian metazoans. These groups have three

patterns of tentacle organization: highly specialized tentacles, less specialized tentacles, and

non-specialized tentacles. Our anatomical and ultra-anatomical data suggest that $O$. borealis

has the least specialized tentacle apparatus, which can be regarded as an ancestral trait. We

propose that the tentacle apparatuses in the Bilateria evolved from the non-specialized

tentacles of deposit/suspension feeders to the highly specialized tentacles of filter-feeders.

\section{Data availability statement}

The data sets analyzed during this study are available from ET upon request.

\section{References}

1. Schmidt-Rhaesa A. The evolution of organ systems. Oxford University Press; 2007.

2. Struck TH, Paul C, Hill N, Hartmann S, Hosel C, Kube M, et al. Phylogenomic analyses unravel annelid evolution. Nature. 2011;471:95-8.

3. Struck TH, Golombek A, Weigert A, Franke FA, Westheide W, Purschke G, et al.

The Evolution of Annelids Reveals Two Adaptive Routes to the Interstitial Realm. Curr Biol. 2015;1-7.

4. Weigert A, Helm C, Meyer M, Nickel B, Arendt D, Hausdorf B, et al. Illuminating the base of the annelid tree using transcriptomics. Mol Biol Evol. 2014 Jun;31(6):1391-401.

5. Weigert A, Bleidorn C. Current status of annelid phylogeny. Org Divers Evol. 2016;16(2):345-62.

6. Andrade SCS, Novo M, Kawauchi GY, Worsaae K, Pleijel F, Giribet G, et al.

Articulating " archiannelids ": Phylogenomics and annelid relationships, with emphasis on meiofaunal taxa. Mol Biol Evol. 2015;

7. Helm C, Beckers P, Bartolomaeus T, Drukewitz SH, Kourtesis I, Weigert A, et al.

Convergent evolution of the ladder-like ventral nerve cord in Annelida. Front Zool.

2018;15(1):36.

8. Wilson D. On the mitraria larva of Owenia fusiformis Delle Chiaje. Philos Trans R Soc London, Ser B. 1932;221:231-334.

9. Liwanow N, Porfirjewa N. Die Organisation der Pogonophoren und deren Beziehungen zu den Polychäten. Biol Zent B1. 1967;86:177-204.

10. Lagutenko Y. Synaptic terminations on basal lamina of epidermis of oweniids (Polychaeta, Oweniidae). Proc Acad Sci USSR. 1987;296(6):1477-9.

11. Lagutenko Y. The ultrastructure of synapses in the primitive intraepidermal nervous system of Myriochele oculata Zachs (Polychaeta, Oweniidae). Tsitologiya. 1993;35(2):2731. 
12. Helm C, Vöcking O, Kourtesis I, Hausen H. Owenia fusiformis-a basally branching annelid suitable for studying ancestral features of annelid neural development. BMC Evol Biol. 2016;16(1):1-19.

691 13. Rimskaya-Korsakova NN, Kristof A, Malakhov V V, Wanninger A. Neural architecture of Galathowenia oculata Zach, 1923 (Oweniidae, Annelida). Front Zool. 2016;13(1):5. Owenia borealis (Annelida: Oweniidae) and their possible relationship with nephridia. J Exp Zool Part B Mol Dev Evol. 2020;334(2).

15. Beckers P, Helm C, Purschke G, Worsaae K, Hutchings P, Bartolomaeus T. The central nervous system of Oweniidae (Annelida) and its implications for the structure of the ancestral annelid brain. Front Zool. 2019;16(1):1-21.

16. Carrillo-Baltodano AM, Seudre O, Guynes K, Martín-Durán JM. Early embryogenesis and organogenesis in the annelid Owenia fusiformis. Evodevo [Internet]. 2021;12(1):5. Available from: https://doi.org/10.1186/s13227-021-00176-Z

17. Erwin DH. The developmental origins of animal bodyplans. In: Neoproterozoic geobiology and paleobiology. Springer; 2006. p. 159-97.

18. Northcutt RG. Evolution of centralized nervous systems: two schools of evolutionary thought. Proc Natl Acad Sci. 2012;109(Supplement 1):10626-33.

19. Hirth F, Kammermeier L, Frei E, Walldorf U, Noll M, Reichert H. An urbilaterian origin of the tripartite brain: developmental genetic insights from Drosophila. Development. 2003; 130(11):2365-73.

20. Arendt D, Tosches MA, Marlow H. From nerve net to nerve ring, nerve cord and brain - evolution of the nervous system. Nat Rev Neurosci. 2016;17(1):61.

21. Bullock T. Annelida, vol 1. In: Bullock T, Horridge G, editors. Structure and function in the nervous system of invertebrates. W. H. Free. San Francisco; 1965. p. 661-789.

22. Richter S, Loesel R, Purschke G, Schmidt-rhaesa A, Scholtz G, Stach T, et al. Invertebrate neurophylogeny: suggested terms and definitions for a neuroanatomical glossary. Front Zool. 2010;7(29):1-49.

23. Purschke G. Annelida: basal groups and Pleistoannelida. In: Schmidt-Rhaesa A, Harzsch S, Purschke G, editors. Structure and evolution of invertebrate nervous systems. Oxford: Oxford University Press; 2015. p. 254-312.

24. Drasche R von. 2. Anatomie von Owenia filiformis. - Wien. 22 pp. In: Beiträge zur feineren Anatomie der Polychaeten Zweites Heft: Anatomie von Owenia fusiformis delle Chiaje. C. Gerold'. Wien; 1885. p. 1-22.

25. McIntosh W. On the nervous system and other points in the structure of Owenia and Myriochele. Ann Mag Nat Hist, Ser 8. 1917;19:233-65.

26. Bubko O, Minichev Y. Nervous system of Oweniidae (Polychaeta). Zool zhurnal. 1972;51(9):1288-99.

27. Lagutenko YP. Early forms of evolution of the basiepidermal nerve plexus of bilateria as a possible evidence for primary diversity of its initial state. J Evol Biochem Physiol. 2002;38(3):354-63.

28. Hejnol A, Lowe CJ. Embracing the comparative approach: how robust phylogenies and broader developmental sampling impacts the understanding of nervous system evolution. Philos Trans R Soc B Biol Sci. 2015;370(1684):20150045.

29. Helm C, Karl A, Beckers P, Kaul-Strehlow S, Ulbricht E, Kourtesis I, et al. Early evolution of radial glial cells in Bilateria. Proc R Soc B Biol Sci. 2017;284(1859):20170743. 30. Martín-Durán JM, Hejnol A. A developmental perspective on the evolution of the nervous system. Dev Biol [Internet]. 2021;475:181-92.

31. Brusca RC, Moore W, Shuster SM. Invertebrates (3 rd edn). Sinauer Associates Inc., Publishers, Sunderland; 2016.

32. Strathmann R. Function of lateral cilia in suspension feeding of lophophorates (Brachiopoda, Phoronida, Ectoprocta). Mar Biol. 1973;23(2):129-36. 
33. Nielsen C. Structure and function of metazoan ciliary bands and their phylogenetic significance. Acta Zool. 1987;68(4):205-62.

34. Riisgård HU, Nielsen C, Larsen PS. Downstream collecting in ciliary suspension feeders: the catch-up principle. Mar Ecol Prog Ser. 2000;207:33-51. 35. Riisgård HU, Larsen PS. Minireview: Ciliary filter feeding and bio- fluid mechanics_-present understanding and unsolved problems. Limnol Oceanogr. 2001;46(4):882-91.

36. Adrianov A V, Malakhov V V, Maiorova AS. Development of the tentacular apparatus in sipunculans (Sipuncula): I. Thysanocardia nigra (Ikeda, 1904) and Themiste pyroides (Chamberlin, 1920). J Morphol. 2006;267(5):569-83.

37. Kuzmina T V, Malakhov V V. Structure of the brachiopod lophophore. Paleontol J. 2007;41(5):520-36.

38. Temereva EN, Malakhov V V. On the organization of the lophophore in phoronids (Lophophorata: Phoronida). Russ J Mar Biol. 2009;35(6):479-89.

39. Temereva EN, Tsitrin EB. Modern data on the innervation of the lophophore in Lingula anatina (Brachiopoda) support the monophyly of the lophophorates. PLoS One. 2015;10(4):e0123040.

40. Temereva EN, Kosevich IA. The nervous system of the lophophore in the ctenostome Amathia gracilis provides insight into the morphology of ancestral ectoprocts and the monophyly of the lophophorates. BMC Evol Biol. 2016;16(1):1-24.

41. Temereva EN, Kuzmina T V. The first data on the innervation of the lophophore in the rhynchonelliform brachiopod Hemithiris psittacea: what is the ground pattern of the lophophore in lophophorates? BMC Evol Biol. 2017;17(1):1-19.

42. Temereva EN. Innervation of the lophophore suggests that the phoronid Phoronis ovalis is a link between phoronids and bryozoans. Sci Rep. 2017;7(1):1-16.

43. Temereva EN. Myoanatomy of the lophophore in adult phoronids and the evolution of the phoronid lophophore. Biol Bull. 2019;237(3):270-82.

44. Temereva EN. Myoanatomy of the phoronid Phoronis ovalis: functional and phylogenetic implications. Zoology. 2019;133:27-39.

45. Kuzmina T V, Temereva EN. Organization of the lophophore in the deep-sea brachiopod Pelagodiscus atlanticus and evolution of the lophophore in the Brachiozoa. Org Divers Evol. 2019;19(1):31-9.

46. Temereva EN. Novel data on the innervation of the lophophore in adult phoronids (Lophophorata, Phoronida). Zoology. 2020;143:125832.

47. Isaeva MA, Kosevich IA, Temereva EN. Peculiarities of Tentacle Innervation of Flustrellidra hispida and Evolution of Lophophore in Bryozoa. In: Doklady Biological Sciences. Springer; 2021. p. 30-3.

48. Santagata S. Phoronida. In: Evolutionary developmental biology of invertebrates 2. Springer; 2015. p. 231-45.

49. Santagata S. Brachiopoda. In: Evolutionary developmental biology of invertebrates 2. Springer; 2015. p. 263-77.

50. Santagata S. Ectoprocta. In: Evolutionary Developmental Biology of Invertebrates 2. Springer; 2015. p. 247-62.

51. Temereva EN. First data on the organization of the nervous system in juveniles of Novocrania anomala (Brachiopoda, Craniiformea). Sci Rep. 2020;10(1):1-15.

52. Capa M, Parapar J, Hutchings P. Phylogeny of Oweniidae (Polychaeta) based on morphological data and taxonomic revision of Australian fauna. Zool J Linn Soc. 2012 Oct;166(2):236-78.

53. Gardiner SL. Fine Structure of the Ciliated Epidermis on the Tentacles of Owenia fusiformis (Polychaeta, weniidae). Zoomorphologie. 1978;91:37-48.

54. Golding DW. Polychaeta: nervous system. In: Gardiner SL, Harrison FW, editors. Microscopic anatomy of invertebrates. New York: Wiley-Liss New York; 1992. p. 153-79. 
55. Koh B-S, Bhaud MR, Jirkov IA. Two new species of Owenia (Annelida: Polychaeta) in the northern part of the North Atlantic Ocean and remarks on previously erected species from the same area. Sarsia North Atl Mar Sci. 2003;88(3):175-88. 56. Schneider CA, Rasband WS, Eliceiri KW. NIH Image to ImageJ: 25 years of image analysis. Nat Methods. 2012;9(7):671-5. Ultrastructure of ganglia in the brachiopod Coptothyris grayi and its phylogenetic significance. J Zool Syst Evol Res. 2021;59(2):376-86.

58. Temereva EN. Phoronida. In: Schmidt-Rhaesa A, Harzsch S, Purschke G, editors. Structure and evolution of invertebrate nervous systems. London: Oxford University Press; 2015. p. 351-359.

59. Mashanov V, Zueva O, Rubilar T, Epherra L, García-Arrarás JE. Echinodermata. In: Schmidt-Rhaesa A, Harzsch S, Purschke G, editors. Structure and evolution of invertebrate nervous systems. Oxford: Oxford University Press; 2015. p. 665-688.

60. Børve A, Hejnol A. Development and juvenile anatomy of the nemertodermatid Meara stichopi (Bock) Westblad 1949 (Acoelomorpha). Front Zool. 2014;11(1):1-14. 61. Jumars PA, Dorgan KM, Lindsay SM. Diet of worms emended: an update of polychaete feeding guilds. 2015;

62. Hansen A. Recherches sur les annélides recueillies par M. le professeur Édouard van Benedon pendant son voyage au Brésil et à la Plata. Mémoires Couronnes Mémoires des Savants Etrang publiés par L'Académie R des Sci des Lettres des B-art Belgique. 1882;44(3):1-29.

63. Phillips Dales R. The feeding mechanism and structure of the gut of Owenia fusiformis delle Chiaje. J Mar Biol Assoc United Kingdom. 1957;36(1):81-9.

64. Ford E, Hutchings P. An analysis of morphological characters of Owenia useful to distinguish species: description of three new species of Owenia (Oweniidae: Polychaeta) from Australian waters. Mar Ecol. 2005;26(3- 4):181-96.

65. Silva L, Lana P. Strategies for tube construction in Owenia caissara (Oweniidae, Annelida) from southern Brazil. Zoology. 2018;129:9-16.

66. Díaz-Díaz O, Parapar J, Moreira J. A new species of genus Owenia Delle-Chiaje, 1844 (Annelida; Oweniidae) from the coast of Venezuela. Cah Biol Mar. 2018;59:589-97. 67. Eckman JE, Nowell ARM, Jumars PA. Sediment destabilization by animal tubes. J Mar Res. 1981;39(2):361-73.

68. Nowell ARM, Jumars PA, Self RFL, Southard JB. The effects of sediment transport and deposition on infauna: results obtained in a specially designed flume. In: Ecology of marine deposit feeders. Springer; 1989. p. 247-68.

69. Self RFL, Jumars PA. Cross-phyletic patterns of particle selection by deposit feeders. J Mar Res. 1988;46(1):119-43.

70. Nicol E. The Feeding Mechanism, Formation of the Tube, and Physiology of Digestion in Sabella pavonina. Earth Environ Sci Trans R Soc Edinburgh. 1931;56(3):53798.

71. Hanson J. Observations on the branchial crown of the Serpulidae (Annelida, Polychaeta). J Cell Sci. 1949;3(11):221-33.

72. Pardos F, Roldan C, Benito J, Emig CC. Fine structure of the tentacles of Phoronis australis Haswell (Phoronida, Lophophorata). Acta Zool. 1991;72(2):81-90.

73. Temereva EN, Tsitrin EB. Development, organization, and remodeling of phoronid muscles from embryo to metamorphosis (Lophotrochozoa: Phoronida). BMC Dev Biol. 2013;13(1):1-24.

74. Rieger RM, Lombardi J. Ultrastructure of coelomic lining in echinoderm podia: significance for concepts in the evolution of muscle and peritoneal cells. Zoomorphology. 1987;107(4):191-208.

75. Fransen ME. Coelomic and vascular systems. In: Ax P, editor. The ultrastructure of Polychaeta Microfauna marina. Stuttgart: G.Fischer Verlag; 1988. p. 199-213. 
76. Bartolomaeus T. On the ultrastructure of the coelomic lining in the Annelida,

846 Sipuncula and Echiura. In: Ax P, editor. Microfauna Marina. Stuttgart: G.Fischer Verlag;

847 1994. p. 1-220.

848 77. Temereva EN. Ultrastructure of the coelom in the brachiopod Lingula anatina. J

849 Morphol. 2017;278(7):997-1011.

850 78. Gardiner SL, Rieger RM. Rudimentary cilia in muscle cells of annelids and echinoderms. Cell Tissue Res. 1980;213(2):247-52.

79. Kuzmina T V, Temereva EN, Malakhov V V. Ultrastructure of the lophophoral coelomic lining in the brachiopod Hemithiris psittacea: functional and evolutionary significance. Zoomorphology. 2018;137(2):257-72.

80. Panganiban G, Irvine SM, Lowe C, Roehl H, Corley LS, Sherbon B, et al. The origin and evolution of animal appendages. Proc Natl Acad Sci U S A. 1997;94(10):5162-6.

81. Tarazona OA, Lopez DH, Slota LA, Cohn MJ. Evolution of limb development in cephalopod mollusks. Prpic-Schäper N-M, Tautz D, Wagner G, editors. Elife. 2019;8:e43828.

82. Shubin N, Tabin C, Carroll S. Fossils, genes and the evolution of animal limbs. Nature. 1997;388(6643):639-48.

83. Tilic E, Rouse GW, Bartolomaeus T. Comparative ultrastructure of the radiolar crown in Sabellida (Annelida). Zoomorphology. 2021;140(1):27-45.

84. Borisanova AO. Two types of the tentacle structure of Entoprocta and the fine structure of the vestibular groove. Zoomorphology. 2020;139(4):433-45.

85. Zhadan A, Vortsepneva E, Tzetlin A. Ontogenetic development and functioning of the anterior end of Cossura pygodactylata Jones, 1956 (Annelida: Cossuridae). Zoomorphology. 2015;134(4):509-21.

86. Bouland C, Massin C, Jangoux M. The fine structure of the buccal tentacles of Holothuria forskali (Echinodermata, Holothuroidea). Zoomorphology. 1982;101(2):133-49.

87. Fankboner P V, Cameron JL. Seasonal atrophy of the visceral organs in a sea cucumber. Can J Zool. 1985;63(12):2888-92.

88. Foster GG, Hodgson AN. Feeding, tentacle and gut morphology in five species of southern African intertidal holothuroids (Echinodermata). African Zool. 1996;31(2):70-9. 89. Graham ER, Thompson JT. Deposit-and suspension-feeding sea cucumbers (Echinodermata) ingest plastic fragments. J Exp Mar Bio Ecol. 2009;368(1):22-9.

\section{Acknowledgements}

We thank Hans Tore Rapp and our colleagues from the University of Bergen for the sampling opportunity at the Espegrend Marine Biological Station, as well as the station staff and especially Tomas Knut Sorelie for collecting the Owenia borealis specimens in the vicinity of the station. We thank the staff of the Cooperative Laboratory of Electron Microscopy of Lomonosov Moscow State University for providing TEM and SEM facilities.

\section{Funding}


888 Federation. Additional support was provided by a Moscow State University Grant for

889 Leading Scientific Schools "Depository of the Living Systems" in frame of the MSU

890 Development Program. The research was carried out as part of the Scientific Project of the

891 State Order of the Government of Russian Federation to Lomonosov Moscow State

892 University No. 121032300121-0.

893 Author information

894 Contributions

895 NR collected and fixed the animals and wrote the Discussion. VD performed the confocal

896 laser scanning microscopical studies. ET designed the study, wrote the manuscript, and

897 prepared all figures.

898 Affiliations

899 Department of Invertebrate Zoology, Biological faculty, Moscow State University, 900 Moscow 119992, Russia

901 Elena Temereva \& Nadezhda Rimskaya-Korsakova

902 National Scientific Center of Marine Biology, Far Eastern Branch, Russian Academy of

903 Sciences, Vladivostok 690041, Russia

904 Vyacheslav Dyachuk

905 National Research University Higher School of Economics, Moscow, Russia

906 Elena Temereva

907 Corresponding author

908 Elena Temereva 


\section{Ethics declarations}

910 Ethics approval and consent to participate

911 Not applicable. The field sampling did not involve endangered or protected species. The use

912 of annelids in the laboratory does not raise any ethical issues.

913 Consent for publication

914 All authors read and approved the manuscript.

915 Competing interests

916 Authors do not have any conflict of interest. All authors have read and approved the

917 manuscript.

918 Additional information

919 Not applicable. 